\title{
The Effects of Shareholder Disagreement under Majority Voting
}

\author{
Carsten Sprenger* \\ International College of Economics and Finance (ICEF), \\ Higher School of Economics, Moscow
}

September, 2007

\begin{abstract}
This paper analyzes investment decisions and share trade when the owners of a firm are not unanimous. We use a one-period model with one firm, two owners and incomplete financial markets. The investment decision is assumed to be made by the majority owner. We study the effects shareholder heterogeneity on the amount of investment, the firm value and aftertrade ownership stakes. As an extension, a protection of the minority owner from unfavorable investment decisions (an outside option or participation constraint) is introduced. When this constraint binds, it does not only change the investment level, but also decreases the concentration of ownership, consistent with cross-country studies that found that minority shareholder protection and ownership concentration are substitutes. When the model is extended by private benefits of control and a second time period, the identity of the majority owner in the second period is endogenously determined in the model. We observe anti-takeover measures by the initial controlling owner at points close to the transfer of control. As for the ownership dynamics, the initial controlling owner typically accumulates shares over time. The model can be applied to post-privatization firms in developing or transition countries. The assumptions of incomplete financial markets (no external finance, no public stock markets) and private benefits of control are particularly appropriate here. The model rationalizes the observed decrease in worker ownership and the increase in managerial ownership after privatization in several countries.
\end{abstract}

Keywords: ownership structure, shareholder unanimity, shareholder voting, Fisher Separation Theorem, incomplete markets, objective of the firm, private benefits of control.

JEL Classification: D21, D52, D92, G32, L21.

${ }^{*}$ I thank Branko Urošević for his advice, and Eva Carceles, Albert Marcet, Christopher Telmer, participants of the 2005 ASSET Conference, the Finance Workshop at University Pompeu Fabra and the ICEF seminar for their comments. All errors and omissions are mine. Correspondence: csprenger@hse.ru 


\section{Introduction}

Conflicts of interests in firms may arise not only between shareholders and managers, as it is studied in most of the corporate finance literature, but also among shareholders. Proxy fights or the purchase of shares in order to gain control over a firm are evidence for different strategies of different groups of shareholders. This observation seems not to be consistent with the assumption of profit maximization as the objective of the firm - an objective on which all shareholders would agree. In this paper, we mean by control the right to decide on the level of investment of the firm. We choose a setting where differences in wealth, initial stake or preferences among shareholders matter for the investment decision and show how they matter. The goal is to analyze investment decisions and share trade when the owners of a firm are not unanimous.

The widespread use of profit maximization in economic models goes back to the Fisher separation theorem. According to the theorem, shareholders unanimously agree on a production plan that maximizes (expected) discounted profits, independently of their preferences and independently of the financial policy of the firm. It was formulated later for a setting with uncertainty by Modigliani and Miller (1958). However, for the theorem to hold, some important conditions have to be satisfied, such as:

1. Financial markets are complete, i.e. the rank of the payoff matrix of all assets in the economy is equal to the number of possible states of the world. ${ }^{1}$

2. There are no externalities between shareholders and the firm, i.e. the firm output only enters shareholders' utility functions via the dividends, not directly.

3. There is perfect competition in the economy.

If either of the three conditions is not fulfilled, shareholders will generally not be unanimous on the firm objective. For example, under incomplete markets and conditions of uncertainty, the investment decision of a firm may alter the risk sharing possibilities in the economy, and shareholders may disagree on how to value the associated contingent payoffs. In any case, decisions have to be made using some social choice mechanism. Here we adopt a simple form of majority voting, the most frequently used mechanism to resolve disagreement among shareholders in practice.

Another motivation for the present paper comes from the observed ownership dynamics of privatized companies in Central and Eastern Europe. Control over firms was often acquired in order to extract private benefits of control, thereby expropriating minority shareholders especially in countries with deficient corporate governance provisions or weak enforcement of the

\footnotetext{
${ }^{1}$ This condition can be weakened by partial spanning conditions, see below.
} 
law. On the one hand, managers, who effectively controlled most firms, could increase their stake in the years after privatization. This is in contrast to shrinking managerial ownership after IPOs in Western firms. ${ }^{2}$ On the other hand, workers who had received large ownership stakes in the privatization in several countries, but presumably did not enjoy significant private benefits, sold shares to other owners in the following years. Our model and its extensions can account for both observations.

In this paper we study the decision-making in a partnership firm with two owners with no uncertainty. Financial markets are incomplete in the sense that there are no assets in the economy with exogenously given payoffs. The only available asset to transfer wealth across time are shares of the firm. Their returns depend on the investment decision of the owners. When the owners differ in wealth, their initial stake or their disposition to substitute consumption across time, they value the returns differently, and thus prefer different amounts of investment. We assume that the decision is made by majority voting, i.e. by the majority owner. Our goal is to study how investment policy, firm value, and share trade are affected by heterogeneity among shareholders. The focus is on the conflict between minority and majority owners. Thus, we abstract from agency problems between shareholders and managers.

Outline of the model. The timing of the basic model is as follows: At time $t=0$, initial shareholders decide on how much to invest given their initial endowments. After that, they are free to trade their shares with each other. At time $t=1$, the production of the firm is realized and distributed according to the after-trade shares. There is no uncertainty. The financial markets are assumed to be incomplete, which in our case means that borrowing and lending are impossible. The investment decision is made by the owner whose initial stake is greater than 50 per cent. ${ }^{3}$ The majority owner can be thought also as a (homogeneous) control group, and the minority owner as many (identical) small shareholders. Using this setup, we obtain results for the level of investment, the value of the firm, and the after-trade shareholdings. The findings are contrasted with the complete markets solution. In that case, borrowing from and lending to exogenous investors are allowed.

The main comparative statics results of the basic model are summarized as follows. The firm invests more if the controlling shareholder is relatively wealthier, ceteris paribus. Relative wealth is the fraction in the endowment of the consumption good that an owner receives initially. The intuition behind this result is as follows: since firm shares are the only asset in the economy, the more investment is needed if higher consumption possibilities have to be spread out over the two dates. Also, investment is higher if the controlling owner holds a smaller initial stake in

\footnotetext{
${ }^{2}$ See Sprenger (2005) for data from a large sample of Russian manufacturing firms, and Mikkelson et al. (1997) for Western firms.

${ }^{3}$ In the case of 50 per cent ownership by both owners a seniority rule applies.
} 
the firm, ceteris paribus. A higher stake obliges her to finance a higher share of the investment, thus she chooses a lower level to achieve a similar consumption profile. The value of the firm is decreasing in the amount of investment since with a high level of investment one needs less shares in order to smooth out consumption over the two dates. As a consequence, the firm value is also decreasing in the relative wealth of the controlling owner and increasing in her initial stake. The final ownership stake of an owner is increasing in her relative wealth, and decreasing in her initial stake. Furthermore, an owner always acquires additional shares if her relative wealth is higher than her initial stake. In the basic model we only impose the constraint that consumption of any owner cannot be negative. It may become binding when the controlling owner is relatively rich and prefers high levels of investment which the minority owner cannot afford. In this case, all the mentioned comparative statics results are reversed.

Differences in the preferences on the intertemporal substitution of consumption between the two owners also affect the level of investment. If returns of the productive technology are relatively low or the initial endowment in the single good is high, a single owner of the firm would invest more the higher his desire for consumption smoothing is. This does however not necessarily happen in the partnership firm. Fixing the preferences of the controlling owner and increasing the desire for consumption smoothing of the non-controlling owner may decrease the level of investment: Since the non-controlling owner cannot influence the investment decision he demands more shares instead and thus drives the price up. The controlling owner exploits this mechanism setting the level of investment even lower in order to sell shares at a higher price. This is an example how the decision on investment and share trade are inter-related.

The majority owner has to take into account in her investment decision its effects on the demand for shares by the non-controlling owner and the share price. But the chosen level of investment may still be unfavorable for the minority shareholder, especially if wealth or initial stakes are distributed extremely unequal. As an extension of the model, we introduce a participation constraint of the minority shareholder, i.e. he can credibly threaten to leave the firm. Alternatively, one can interpret it as a better protection of the rights of minority shareholders. Then, his/her interest has to be taken into account in the investment decision when the constraint binds. For example, if the controlling owner is very rich, the participation constraint lowers investment. It also prevents her to acquire the entire firm. In all cases where the participation constraint binds, it lowers ownership concentration as compared to the basic model. This is consistent with the empirical finding of La Porta et al. (1998) that investor protection and ownership concentration are substitutes.

In another extension of the basic model we assume that one of the shareholders has private benefits of control, i.e. she can extract a higher payoff from the firm at time $t=1$ than what 
would correspond to her ownership stake. This externality between the firm and its shareholders invalidates the Fisher separation theorem for this case. Even with complete financial markets, the two shareholders do not agree on the level of investment. A higher fraction of private benefits increases investment under complete markets. In the incomplete markets model, this is only the case if the controlling owner's initial stake is higher than her relative wealth. In contrast to the basic model, there is share trade even if relative wealth and initial stake are equal. In this case, the controlling owner reduces her stake in order to smooth consumption in the presence of an extra payoff (the private benefit) at time $t=1$.

When we further extend the model with private benefits to two periods, share trade at time $t=0$ may change the identity of the majority owner. To our knowledge, multi-period models with a majority decision on investment and share trade in every period have not been analyzed in the literature so far. Concerning the power to decide on investment and the allocation of private benefits, we distinguish the following cases: A ("Non-transferable control") - the right to make the investment decision and private benefits always accrue to the initial majority owner no matter what the ownership distribution is, B ("Partial control") - the right to decide on investment at $t=1$ goes to the majority owner after the first round of share trade, but private benefits stay with the original majority owner, C ("Full control via majority") — both control and private benefits are transferred to the new majority owner. We compare the results with a two-period version of the basic model without private benefits (case D). In cases B and C we observe a kind of anti-takeover behavior of the controlling owner. At values of relative wealth close to the point where the control transfer occurs, she reduces investment in order to keep her ownership stake at exactly 50 per cent. A misalignment of private benefits and control over investment as in case B is bad for investment and leads typically to lower utility of both owners than in cases A and C. As for the ownership dynamics, the initial controlling owner acquires shares in both trading rounds if her relative wealth is not considerably smaller than her initial stake.

The assumptions of our model mimic the environment of firms in the transition countries of Eastern Europe after privatization: they had almost no access to external finance, shares were typically not traded on public stock markets with outsiders, and managers were able to extract large private benefits of control. The results of the model in terms of changes in the ownership structure can explain the observations on the dynamics of ownership in these firms mentioned at the beginning. Workers often received large ownership stakes during privatization, but can be assumed to be the least wealthy shareholders. It is therefore not surprising that they sold part of their ownership stakes as predicted by the model. Managers, however, accumulated shares in their firms together with some affiliated parties during the years following privatization. This is consistent with the finding from the two-period model with private benefits. 
Related literature. This paper is related to various strands of literature. First, it relates to the literature on firm objectives under incomplete markets. ${ }^{4}$ The production decision in a stock market economy is usually analyzed in one-period, one good models with uncertainty. One group of contributions, including seminal papers such as Diamond (1967), Ekern and Wilson (1974) and Radner (1974), formulate restrictions on the production plan of a firm, which restore the unique equilibrium of complete markets where all shareholders agree to maximize expected discounted profits. These restrictions are referred to as partial spanning conditions ${ }^{5}$, and mean essentially that a firm cannot create an asset with a vector of contingent payoffs that is independent of existing assets in the economy. Grossman and Stiglitz (1980) show that spanning is not enough to ensure unanimity if consumers receive information on the future production of the firm after the investment decision and can trade shares on that information. With an additional competitivity assumption ${ }^{6}$ not only unanimity is restored, but the common objective of shareholders is net value maximization - the same as under complete markets. Carceles-Poveda and Coen-Pirani (2005a) have shown conditions that imply partial spanning for the neoclassical growth model with capital and labor inputs: If the production function exhibits either constant returns to scale or is of the Cobb-Douglas type ${ }^{7}$, and if there is a continuum of identical firms, then unconstrained shareholders are unanimous about the investment decision. Carceles-Poveda and Coen-Pirani (2005b) show in turn the conditions for equivalence between general equilibria with value-maximizing firms ${ }^{8}$ and equilibria in the setup with households renting capital to firms, which is used in the macroeconomic literature on incomplete markets (e.g. Aiyagari (1994)).

In another group of contributions, disagreement among shareholders is taken for granted, and the authors search for objective functions based on some collective decision-making mechanism. Our paper belongs to this group. It seems reasonable to look at the firm's problem when shareholders are not unanimous, since partial spanning conditions are quite restrictive and are not satisfied under different and equally plausible theoretical assumptions, such as: production functions with decreasing returns of other types than Cobb-Douglas, heterogeneous firms, idiosyncratic shocks to firm productivity, a finite set of firms, binding short-sale constraints or externalities. Needless to say that diverging interests of shareholders are also observed frequently in practice. Drèze (1974) and Grossman and Hart (1979) introduce side payments, such that shareholders favoring a new production plan may compensate the others for incurred losses. This leads to a criterion to find the optimal investment that is based on contingent future profits discounted by a

\footnotetext{
${ }^{4}$ For extensive surveys of this literature see Drèze (1987) and Magill and Quinzii (1996, Chapter 5).

${ }^{5}$ Drèze (1987) shows that Diamond's assumption of multiplicative uncertainty is a special case of partial spanning.

${ }^{6}$ This assumption says that shareholders perceive ex-ante that their production decision for a particular firm does not affect the share price of other firms.

${ }^{7}$ St-Pierre (2005) derives a more general separability condition for the production function that yields the unanimity result.

${ }^{8}$ That requires unanimity among shareholders in the control group.
} 
weighted average of shareholders' stochastic discount factor (present value vector). Both papers differ in giving the decision making power to initial (Grossman-Hart) or after-trade shareholders (Drèze), and the weights are given accordingly by the initial or final stakes. If initial shareholders make the investment decision in a one-period model, they have to take into account the effect of the investment decision on the share price. Therefore, this setup extends more easily to several periods. The timing in our basic model and equilibrium definitions follow mainly Grossman and Hart (1979). However, instead of the possibility of side-payments between shareholders we assume that decisions are made by majority voting.

Several authors have included voting among shareholders in their models of stock market economies. Drèze (1985) assigns decision making power to a control group, which consists of a subset of shareholders or other stakeholders. Production decisions must be approved unanimously by a control group and a by majority of shareholders. Existence of an equilibrium of production and exchange can be shown (Drèze, 1989). A general proof of existence of equilibria in economies where firms' decisions are made by a collective choice of shareholders is given in Kelsey and Milne (1996). Possible decision rules include veto power of a control group and generalized median voter rules. DeMarzo (1993) characterizes equilibria resulting from majority voting of shareholders and shows that these imply that production is optimal for the largest shareholder. In our model we intend to be more specific about the effects of different interests among shareholders on investment, share prices and the change in the stakes of each owner.

A second strand of literature, which is related to our paper, deals with ownership structure under the presence of a large shareholder (see Admati et al. (1994) for a static, and DeMarzo and Urošević (2006) for a dynamic setup). These papers model a tradeoff between the desire for diversification and shared benefits of control of a large shareholder. Payoffs are influenced by the monitoring effort of the large shareholder. Edelstein et al. (2005) add private benefits of control to this setup. Instead of assuming individual effort with an instantaneous payoff, we explicitly model production, which takes time (one period), and requires a collective decision on the amount of investment (the main interest of this paper).

Third, our paper is related to the literature on corporate governance, as summarized in Bolton et al. (2003) and Shleifer and Vishny (1997). We investigate the effects of different corporate governance rules, such as the protection of minority shareholders (section 3.1) and different rules for the allocation of private benefits of control (section 3.3). Massa and Simonov (2005) study the relation between shareholder composition and the value of the firm. They find that the degree of shareholder homogeneity in beliefs on the true firm value affects firm value positively. In our model, differences of interest among shareholders do not stem from asymmetric information, but rather from differences in endowments or preferences. Homogeneity, i.e. identical endowment or 
preferences, does in general not maximize investment or the firm value in our model.

Lastly, we contribute to the literature on financing imperfections and firm investment, as summarized in Hubbard (1998). Our paper suggests that in the presence of financial constraints, not only information costs and internal funds of the firm, but also the wealth, initial stake, and preferences of the firm owners determine the investment decision.

Organization of the paper. The paper is organized as follows: Section 2 presents the basic model. Subsection 2.1 states the model assumption and subsection 2.2 introduces the notions of an exchange equilibrium and an production-exchange equilibrium. Subsection 2.3 analyzes the model for the case when owners differ in their initial wealth and ownership stakes. The main proposition states how initial endowments affect the investment decision, the firm value and after-trade ownership stakes. We contrast the results with a model of complete markets (developed in Appendix B), where the owners can borrow from and lend to exogenous investors. Subsection 2.3 analyzes the model for the case when owners differ in their preferences on intertemporal substitution of consumption. Section 3 extends the model in several dimensions. In subsection 3.1 we introduce a participation constraint and determine numerically optimal investment, firm value, and ownership stakes, with and without the additional constraint. We consider both differences among shareholders in their initial endowments and in their preferences on intertemporal substitution. Subsection 3.2 introduces private benefits of control and analyzes the model in one period, both for complete and incomplete markets. In neither setup the Fisher separation theorem holds, but the effects of private benefits on the investment decisions are different. Subsection 3.3 presents the model with private benefits in two periods, with repeated production and trading. Section 4 concludes. Appendix A contains all longer proofs of propositions and details of calculations. Appendix B develops a complete markets version of the basic model and confirms that the Fisher separation theorem holds in this setup. Appendix $\mathrm{C}$ analyzes the basic model with a more general utility function.

\section{The basic model}

\subsection{Model formulation}

We analyze the problem of different shareholder interests in a deterministic model. There are two dates, 0 and 1 . The technology is defined by a a Cobb-Douglas production function, which related a single input $y_{0}$ to output $y_{1}$ :

$$
-y_{0}=k ; y_{1}=A k^{\alpha}
$$


where $\alpha \in(0,1)$, and $A>0$ is a constant indicating the level of technology. $k$ represents the initial capital investment.

There is one firm in the economy with two owners, indexed by $i=1,2$. Each owner $i$ is endowed initially with a share in the firm $\bar{\theta}^{i} \in(0,1)$. The total number of shares is normalized to one, i.e. $\bar{\theta}^{1}+\bar{\theta}^{2}=1$. The only asset that can be used to transfer wealth between the two dates are the shares of the firm. Every owner also has an initial endowment in the (sole) consumption good $\omega^{i}$. Let $\omega$ denote the aggregate endowment, and let owner 1 receive the fraction $\beta \in[0,1]$ of this endowment. That is, the initial wealth of the two owners is given by $\omega^{1}=\beta \omega$ and $\omega^{2}=(1-\beta) \omega$. We call $\beta$ the relative wealth of owner 1 , and $1-\beta$ the relative wealth of owner 2 . The timing of actions is depicted in the following figure.

\begin{tabular}{|c|c|c|}
\hline \multicolumn{2}{|c|}{$\begin{array}{c}\text { Decision on investment } k, \\
\text { then share trade }\left(\theta^{i}, p\right)\end{array}$} & $\begin{array}{c}\text { Dividend } \\
\text { payout } \theta^{i} A k^{\alpha}\end{array}$ \\
\hline \multirow{2}{*}{$\begin{array}{l}\text { Endow- } \\
\text { ments } \\
\omega^{i}, \bar{\theta}^{i}\end{array}$} & L & \\
\hline & $t=0$ & $t=1$ \\
\hline
\end{tabular}

Figure 1: Time line of the basic model

The initial investment $k$ is financed proportional to the initial ownership stakes $\bar{\theta}^{i}, i=1,2$. After that, the owners may trade their shares at market value $p$. The post-trade ownership stakes are denoted by $\theta^{i}$. The budget constraint for time $t=0$ reads

$$
c_{0}^{i}=\omega^{i}+\left(\bar{\theta}^{i}-\theta^{i}\right) p-\bar{\theta}^{i} k
$$

In words, owners allocate their endowments and the net proceeds from share trade to consumption and investment. Afterwards, at time $t=1$, the owners consume the dividends of the firm according to their stakes after trade, so the budget constraint for date 1 reads

$$
c_{1}^{i}=\theta^{i} A k^{\alpha}
$$

We follow Grossman and Hart (1979) in placing the decision on a production plan in the hands of the initial shareholders. In a one-period model, initial owners take into account the effect of the production decision on the share price, while post-trade (final) shareholders would not. This setting can be more easily extended to more than multiple periods - final shareholders would then be the initial shareholders in the next period, and would have to be treated like initial shareholders in a one-period model, i.e. the effect of their investment decision on the value of the firm has to be taken into account.

This model is an incomplete market model in the following sense: there is one state of the world at date 1 , but there is no asset with exogenously given payoff. 
The utility function is assumed to be logarithmic. ${ }^{9}$ The expected utility function for owner $i$ is time-additive and reads

$$
U^{i}=\ln c_{0}^{i}+\delta \ln c_{1}^{i}
$$

where $\delta$ is the (objective) discount factor.

\subsection{The notion of equilibrium}

In this section, we provide the tools for the analysis of the model outlined above. Substituting the constraints (2) and (3) into the expected utility function (4) leads to the following objective function

$$
U^{i}=\ln \left[\omega^{i}+\left(\bar{\theta}^{i}-\theta^{i}\right) p-\bar{\theta}^{i} k\right]+\delta \ln \left[\theta^{i} A k^{\alpha}\right], \quad i=1,2
$$

We solve the model backward in time, starting with the decision on the optimal ownership stakes. Therefore, we define first the notion of an exchange equilibrium.

Definition 1 (Exchange equilibrium). For a given investment plan $k$, given initial endowments of the consumption good $\left(\omega^{i}\right), i=1,2$ and initial shareholdings $\left(\bar{\theta}^{i}\right), i=1,2$, an exchange equilibrium is the pair of vectors of consumption and ownership stakes in the firm $\left(c^{i}, \theta^{i}\right), i=1,2$ and a firm market value $p$, such that (i) owners $i=1,2$ maximize (5) with respect to $\theta^{i}$, and (ii) the market for shares clears, i.e. $\theta^{1}+\theta^{2}=1$.

The definition implies that owners are price-takers. One way to motivate it, is to think of the two owners as many owners of two types. ${ }^{10}$ From (i) and (ii), we get the optimal stakes of the two owners as well as the firm value as functions of the level of investment $k$. By substituting these functions into (5) we obtain the indirect utility functions $V^{i}(k), i=1,2$.

The next step is to go from the exchange equilibrium with a fixed production plan to a production equilibrium. In our model, as we will show in section 2.3 , there is no unanimity among shareholders about the optimal level of investment. For this reason, we have to specify the decision making within the firm.

We do not follow a normative approach, rather we assume that majority voting is the rule. In our model, this means that one of the partners decides, and without loss of generality we assume that $\bar{\theta}^{1} \geq 0.5$. For the limiting case of $\bar{\theta}^{1}=\bar{\theta}^{2}=0.5$ we assume that the "senior" owner 1 decides.

\footnotetext{
${ }^{9}$ Appendix $\mathrm{C}$ presents the basic model with the constant relative risk aversion utility function which includes log utility as a special case.

${ }^{10}$ The reader may want to check with equation (9) that if initial endowments and stakes are split equally among with $n$ owners of the same type, also the after-trade ownership stake of each individual is the $n$-th part of the after-trade ownership stake. Thus, there is no problem of aggregation.
} 
Then the optimal investment decision is the result of the following maximization problem

$$
\begin{aligned}
\max _{k} V^{1}(k) \quad \text { s.t. } & c_{t}^{i} \geq 0, \quad i=1,2, \quad t=0,1 \\
& \text { and budget constraints (2) and (3) }
\end{aligned}
$$

Owner 1 decides on the production plan subject to non-negativity constraints for consumption of each owner at time $t=0$ and the budget constraints. Note that these constraints imply that investment $k$ lies between zero and the total endowment $\omega \cdot{ }^{11}$ We are now able to define a production-exchange equilibrium.

Definition 2 (Production-exchange equilibrium). For given initial endowments of the consumption good $\left(\omega^{i}\right), i=1,2$ and initial shareholdings $\left(\bar{\theta}^{i}\right), i=1,2$, a production-exchange equilibrium is a pair of vectors of consumption and and ownership stakes in the firm $\left(c^{i}, \theta^{i}\right), i=1,2$, a firm market value $p$ and a level of initial investment $k$, such that the conditions (i) and (ii) of the exchange equilibrium are satisfied, and (iii) the majority owner chooses a level of initial investment $k$ that solves (6).

\subsection{Analysis for owners with different initial endowments}

In this section, we allow for differences between owners in the endowments only, and investigate their impact on investment, firm value and after-trade ownership stakes. Solving for the exchange equilibrium provides us expressions for the firm value (price of a 100 per cent stake in the firm) and the optimal ownership stake of each owner as functions of investment: ${ }^{12}$

$$
\begin{aligned}
p(k) & =\delta(\omega-k) \\
\theta^{i}(k) & =\frac{\omega^{i}+\bar{\theta}^{i}(p(k)-k)}{\omega+p(k)-k} \\
& =\frac{\omega^{i}+\bar{\theta}^{i}(\delta \omega-(1+\delta) k)}{(1+\delta)(\omega-k)}
\end{aligned}
$$

Note that the price is a negative function of investment. A high level of investment means that one needs less shares in order to smooth out consumption over the two dates. Hence, with an increasing amount of investment, demand for shares and their price go down. As discussed in Appendix $\mathrm{C}$ for the class of CRRA preferences, this is true only if the elasticity of intertemporal substitution is not too high. For owners which are nearly risk-neutral (i.e. whose elasticity is very large), investment affects the firm value positively.

\footnotetext{
${ }^{11}$ To see this, note that from $(2), c_{0}^{1}+c_{0}^{2}=\omega-k \geq 0$. Even if $c_{0}^{2}=0$, owner 1 chooses a level of investment such that $c_{0}^{1}>0$ since zero consumption would give the lowest possible level of utility. It follows that $\omega-k>0$.

${ }^{12}$ More details of the calculations are given in Appendix A.1.
} 
The following proposition gives a simple condition when owners sell or buy additional shares in the trading stage.

Proposition 1. An owner acquires (sells) shares whenever her relative wealth is higher (smaller) than her initial ownership stake. In the case of owner 1 this condition is $\beta>\bar{\theta}^{1}\left(\beta<\bar{\theta}^{1}\right)$. For $\beta=\bar{\theta}^{1}$, no share trade takes place.

Proof. We use (9) to write the change in the asset position of owner $i$

$$
\theta^{i}(k)-\bar{\theta}^{i}=\frac{\omega^{i}-\bar{\theta}^{i} \omega}{(1+\delta)(\omega-k)}
$$

For owner 1, this is

$$
\theta^{1}(k)-\bar{\theta}^{1}=\frac{\left(\beta-\bar{\theta}^{1}\right) \omega}{(1+\delta)(\omega-k)}
$$

This expression is positive (i.e. owner 1 acquires shares) whenever $\beta>\bar{\theta}^{1} .{ }^{13}$ The other cases follow similarly.

In order to solve for the production-exchange equilibrium we have to find the optimal level of initial investment. As stated in problem (6) we maximize the indirect utility function of the controlling owner, owner 1 (since by assumption $\bar{\theta}^{1} \geq 0.5$ ):

$$
V^{1}(k)=\ln \left[\beta \omega+\left(\bar{\theta}^{1}-\theta^{1}(k)\right) p(k)-\bar{\theta}^{1} k\right]+\delta \ln \left[\theta^{1}(k) A k^{\alpha}\right]
$$

We characterize first the interior solution where the non-negativity constraints for consumption do not bind. Intermediate steps of the calculations are given in Appendix A.2. The first-order condition yields a quadratic equation characterizing the unconstrained optimal investment with the solution

$$
k^{i n t}=\left(-\frac{P}{2}-\sqrt{\frac{P^{2}}{4}-Q}\right) \omega
$$

where

$$
\begin{aligned}
P & =\frac{(1-\alpha) \beta}{(1+\delta)\left(\delta^{-1}+\alpha\right) \bar{\theta}^{1}}-\frac{1+2 \delta}{1+\delta} \\
Q & =\frac{\alpha\left(\beta+\delta \bar{\theta}^{1}\right)}{(1+\delta)\left(\delta^{-1}+\alpha\right) \bar{\theta}^{1}}
\end{aligned}
$$

At corner solutions, the level of investment $k$ is determined such that consumption at date $t=1$ of the non-controlling owner 2 is equalized to zero. ${ }^{14}$ We obtain

$$
k^{\text {constr }}=\frac{1-\beta+\delta\left(1-\bar{\theta}^{1}\right)}{\left(1-\bar{\theta}^{1}\right)(1+\delta)} \omega
$$

\footnotetext{
${ }^{13}$ Note that the denominator is always positive since $k<\omega$.

${ }^{14}$ It turns out that if the constraint of non-zero consumption at time $t=0$ binds, so does the constraint of non-zero consumption at time $t=1$. Thus, only the latter one has to be taken into consideration. Also we will show below that the constraints for owner 1 do never bind. See Appendix A.2.
} 
The constraint of non-negative consumption is binding whenever the level of investment $k$, optimally chosen by owner 1 , is higher than or equal to the level that leads to zero consumption of owner 2 at time $t=1$. That is, the condition for the constraint to bind is

$$
-\frac{P}{2}-\sqrt{\frac{P^{2}}{4}-Q} \geq \frac{1-\beta+\delta\left(1-\bar{\theta}^{1}\right)}{\left(1-\bar{\theta}^{1}\right)(1+\delta)}
$$

Equations (12) to (16) fully characterize the production-exchange equilibrium of the basic model of incomplete markets.

Appendix B shows the results of a model with complete markets. There, we make the same assumptions as we do here, except that owners are allowed to borrow from or lend to exogenous investors at some given interest rate. Since the Fisher Separation theorem holds in that setting, investment does not depend on any individual characteristics of the owners. It only depends on the technological parameters and the interest rate. In contrast, in the model of incomplete markets analyzed here, the desired level of investment of owner 1 depends on her relative wealth $\beta$ and the initial stake $\bar{\theta}^{1}$. A similar condition holds for owner 2, and since endowments may be different across owners, both optimality conditions will in general not coincide. Therefore, shareholders do not agree on how much to invest. Note also that the firm value is an increasing function of investment if markets are complete, but a decreasing function in our model. Lastly, ownership stakes are determined in our model, but indeterminate under complete markets.

Example 1 (Proportional endowments). Consider the special case where relative wealth and initial ownership stake coincide, i.e. $\beta=\bar{\theta}^{1}$. We know from Proposition 1 that in this case there is no share trade in equilibrium, i.e. $\bar{\theta}^{1}=\theta^{1}$. The indirect utility function for owner $i$ then simplifies to

$$
\begin{aligned}
V^{i}(k) & =\ln \left[\bar{\theta}^{i}(\omega-k)\right]+\delta \ln \left[\bar{\theta}^{i} A k^{\alpha}\right] \\
& =\ln (\omega-k)+\delta \alpha \ln k+\delta \ln A+(1+\delta) \ln \bar{\theta}^{i}
\end{aligned}
$$

The last term is just a constant, so the optimal level of investment $k$ does not depend on the individual variables $\beta$ and $\bar{\theta}^{1}$ in this special case. Thus, shareholders will be unanimous. The optimal level of investment is given by $k=\frac{\alpha \delta}{1+\alpha \delta}$.

How do differences in the endowments of cash and shares between the two owners influence the optimal level of investment $k$, the firm value $p$ and the stake of each owner in the firm after trade? In the following proposition we state some comparative statics results and use them to further characterize the solution.

Proposition 2. At interior solutions to the production-exchange equilibrium,

(i) the optimal level of investment $k$ is an increasing function of the relative wealth of the controlling shareholder, $\beta$, and a decreasing function of her initial ownership stake, $\bar{\theta}^{1}$, 
(ii) the value of the firm $p$ is decreasing in $\beta$, and increasing in $\bar{\theta}^{1}$, and

(iii) the after-trade ownership stake of owner $1, \theta^{1}$, is increasing in $\beta$, and decreasing in the initial ownership stake $\bar{\theta}^{1}$.

(iv) At corner solutions, all comparative statics results in (i) and (ii) are reversed. The after-trade ownership stake of owner 1 is constant and equal to one.

(v) The non-negativity constraint for consumption of owner 2 at time $t=1$ can be binding only if $\beta>\bar{\theta}^{1}$. Given this, it is more likely to be binding the higher is $\beta$, and the lower is $\bar{\theta}^{1}$.

(vi) The non-negativity constraints for consumption of the controlling owner 1 are never binding.

Proof. See Appendix A.3.

Part (i) says simply that as owner 1 becomes relatively richer, she can afford to save and invest more for tomorrow's consumption. As for the effect of the initial ownership stake, there are two effects at work. First, a higher $\bar{\theta}^{1}$ means that owner 1 has to put a higher fraction of investment. In order not to drive down consumption today, she chooses a smaller $k$. Second, when $\bar{\theta}^{1}$ is higher, owner 1 can sell shares to owner 2 and use the revenues for consumption and investment. This effect leads to a higher $k$. It turns out that in equilibrium the first effect dominates.

A similar result is obtained in the model of a monopolistic firm in general equilibrium by Yalcin and Renström (2003). If the relative labor endowment of a shareholder is equal to his initial stake, he wants the firm to act as a competitive firm. If the relative labor endowment of a shareholders is higher (lower) than his initial stake he prefers a higher (lower) level of production than the competitive level.

Part (ii): Recall that in our model, the value of the firm is a decreasing function of investment. As owner 1 becomes relatively richer ( $\beta$ increases), she invests more while owner 2 would prefer less. Thus, shares are worth less to owner 2, and the price goes down. ${ }^{15}$ As shown in Appendix $\mathrm{C}$, the price may be increasing in the level investment and thus with $\beta$ only if owners' readiness to substitute consumption across time is very high. ${ }^{16}$ In this case owners take advantage of a very productive technology and tolerate to consume few amounts initially.

Part (iii): The parameters $\beta$ and $\bar{\theta}^{1}$ affect the after-trade ownership stake of owner 1 both directly and indirectly via their effect on the optimal level of investment, see equation (10). As for relative wealth $\beta$, a higher value has a direct positive effect on the after-trade ownership stake. Since it also affects investment positively, which in turn affects the final ownership stake, the indirect effect depends on the sign of $\beta-\bar{\theta}^{1}$. It is positive if $\beta>\bar{\theta}^{1}$ and negative if $\beta<\bar{\theta}^{1}$. For this last case, however, it turns out that the direct effect is dominant in equilibrium, such that $\beta$

\footnotetext{
${ }^{15}$ Recall that share trade takes place after the investment decision.

${ }^{16}$ Within the class of CRRA utility functions, the parameter of relative risk aversion has to be near zero, and in any case lower than 1 (corresponding to log utility).
} 
affects the final stake of owner 1 positively for all possible values of $\beta$.

Part (iv): If the non-negativity constraint for consumption of owner 2 at date $t=1$ binds, it forces the controlling owner to lower investment, and more so the higher is her relative wealth or the lower is her initial stake. This implies for the price of shares that with increasing relative wealth of owner 1 , shares become more attractive again to owner 2 , and the price increases. The corner solution always implies that the controlling owner acquires the entire firm in the trading round.

Part (v): We can have corner solutions only if owner 1's relative wealth is higher than her initial stake. The larger this difference, the higher is the desired level of investment of owner 1 until it reaches a level where the poorer owner 2 cannot afford it since his consumption would go to zero.

Part (vi): Owner 1 will never choose investment levels that drive her own consumption to zero at any date, and it turns out that this is neither the case at corner solutions. Effectively, the only constraint that has to be taken into account is the non-negativity constraint of date $t=1$ consumption of owner 2 .

Numerical solutions that take the non-negativity of consumption and further constraints into account are presented in section 3.1.

\subsection{Analysis for owners with different preferences on intertemporal substitu- tion}

In addition to their wealth, the owners can differ in their willingness to substitute consumption between the two dates. Different preferences on intertemporal substitution generate, in general, disagreement among owners about the preferred level of investment. ${ }^{17}$ In this section, the preferences of the controlling owner 1 are described as before by log utility, but owner 2's preferences are given by a CRRA utility function with coefficient of relative risk aversion $\gamma \geq 0$. For values of $\gamma$ smaller than 1, owner 2 is more willing to substitute consumption at one date by consumption at the other date, and for values of $\gamma$ larger than 1 , he would have a stronger interest of smoothing consumption across time as compared to owner $1 .{ }^{18}$ Appendix A.4 lists the demand functions for shares of the two owners and an implicit expression for the value of the firm $p(k)$. The value of the firm and the optimal level of investment $k$ are found numerically.

How do investment, and consequently firm value and ownership stakes, depend on differences in preferences, in particular on the value of $\gamma$ in the utility function of owner 2? The answer

\footnotetext{
${ }^{17}$ This can be seen from the optimality condition for investment when both owners have CRRA utility functions, see appendix C.

${ }^{18}$ The elasticity of intertemporal substitution is given by $1 / \gamma$.
} 
depends on how the preferred level of investment of owner 2 changes with $\gamma$. For a relatively unproductive technology (low $A$ ) and a high level of the endowment $\omega$, the preferred investment is an increasing function of $\gamma$ : an owner with no interest in consumption smoothing will invest low amounts since returns are low, but an owner with a higher $\gamma$ would invest higher fractions of the endowment in order to smooth consumption across time. In contrast, preferred investment will be decreasing if returns are high and the endowment is relatively small. An exact condition is given at the end of Appendix C.

To see how differences in preferences affect the outcomes in the partnership firm, we conduct a numerical analysis. We assume that the two owners are equally endowed with shares and the consumption good, i.e. $\bar{\theta}^{1}=\beta=0.5$, in order to isolate the effects of different endowments from differences in preferences. We look both at the case where the preferred investment of owner 2 is increasing in $\gamma$ (we let $A=1$ ) and where it is decreasing $(A=2)$. The rest of the parameter values are set at $\omega=1, \alpha=0.5$ and $\delta=0.99$. The following graphs display the endogenous variables of the model, investment $k$, firm value $p$ and share purchase of owner $1, \theta^{1}-\bar{\theta}^{1}$, as functions of different values of $\gamma$ in the utility function of owner 2. The first row of graphs refers to the case where $A=1$ and the second to $A=2$.
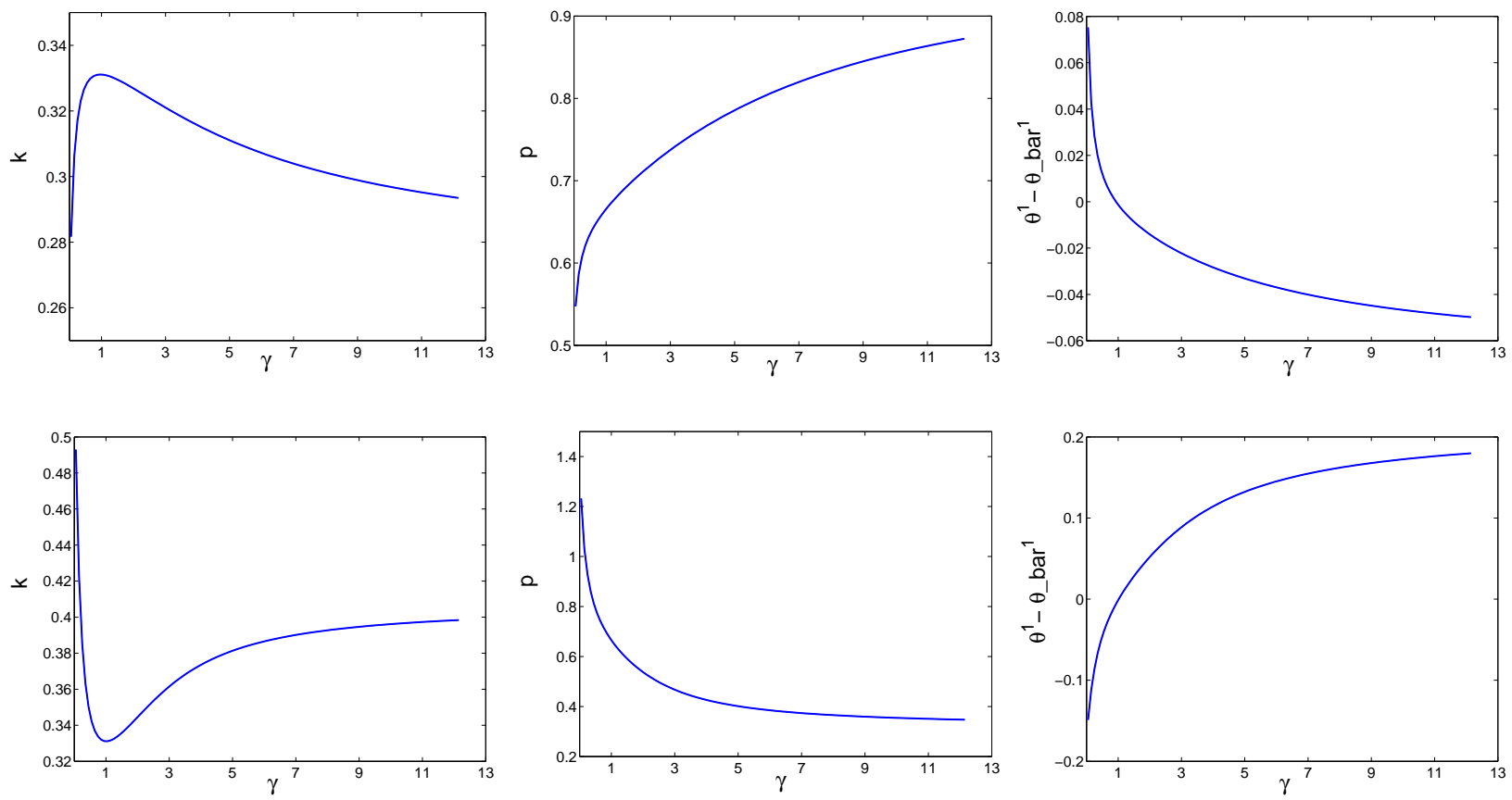

Figure 2: Optimal investment $k$, firm value $p$ and the purchase of shares by owner $1\left(\theta^{1}-\bar{\theta}^{1}\right)$, as functions of the value of $\gamma$ in the utility function of owner 2. First row of graphs: $A=1$, second row: $A=2$.

Consider first the case of relatively low returns where owner 2 (if he were the sole owner of the firm) would increase investment the higher the value of $\gamma$ is in his utility function - depicted in the first row of graphs. If $\gamma>1$, owner 2 has a stronger preference for consumption smoothing 
than owner 1, and he would like to invest more than the latter. But since he cannot influence the decision directly, he instead demands more shares, and drives the price up. The controlling owner exploits this mechanism and sets $k$ even lower (as $\gamma$ increases) in order to sell shares at a higher price. Here we have an example how the decision on investment and share trade are interrelated. In the case where $\gamma<1$, i.e. owner 2 is more willing to substitute consumption across time than owner 1. The controlling owner 1 decides to invest low amounts (since the technology offers relatively low returns) and acquires shares in order to smooth consumption. The level of investment is however above the preferred level of owner 2 to make the latter sell at a lower price. As a result, the level of investment is highest when shareholders have the same preferences $(\gamma=1)$ and are therefore unanimous.

Exactly the opposite occurs when the technology offers relatively high returns (see the second row of graphs). With increasing desire for consumption smoothing (increasing $\gamma$ ), owner 2 would like to invest less, but owner 1 invests more if $\gamma>1$ and as $\gamma$ increases. The result is that owner 2 has to sell shares at a low price if he wants a more or less equalized consumption profile over time. Investment reaches a minimum when shareholders are unanimous.

Example 2 (Infinite elasticity of substitution). It is interesting to calculate the limiting case where owner 2 is completely indifferent between consuming today or tomorrow $(\gamma=0)$. In this case, there is only one price at which owner 2 has a finite demand for shares: $p=\delta A k^{\alpha}$. At this price he is indifferent between any amount of shares. The after-trade ownership stake of owner 1 as a function of $k$ is given by

$$
\theta^{1}(k)=\frac{\beta \omega+\bar{\theta}^{1}\left(\delta A k^{\alpha}-k\right)}{(1+\delta) A k^{\alpha}}
$$

where we substituted the price above into the demand function for shares (equation 43) in appendix A.4. This yields an indirect utility function for owner 1 of the following form

$$
V^{1}(k)=(1+\delta) \ln \left[\beta \omega+\bar{\theta}^{1}\left(\delta A k^{\alpha}-k\right)\right]-\ln [1+\delta]
$$

which leads to the investment rule $k=(\delta A \alpha)^{\frac{1}{1-\alpha}}$. This, however, is the same result as if both owners had $\gamma=0$ (see Appendix $\mathrm{C}$ for a discussion). So whenever one owner is completely indifferent between consuming today or tomorrow, there is unanimity about the preferred level of investment. Furthermore, the other owner can smooth consumption perfectly since the owner with infinite elasticity is indifferent between any amount of shares held (as long as consumption is positive). 


\section{Extensions}

In this section, we extend the basic model in several ways. First, we give an outside option to the minority shareholder, which improves his bargaining position. So far, differences of interest between shareholders and changes in the ownership distribution were derived without referring to asymmetric information or moral hazard problems. In a second extension, we assume that one of the owners is able to extract a constant share of profits as private benefits of control. This model is also extended to two periods (three dates).

\subsection{Participation constraint}

Giving the controlling shareholder all decision rights ignores the bargaining power of minority shareholders. In this extension, we assume that the minority shareholder can vote with his feet, which means that he can make a credible threat to leave the firm. In particular, we assume that both owners are needed to operate the firm technology. ${ }^{19}$ The outside option is a single proprietor firm with a somewhat inferior technology. It is given by

$$
-y_{0}=m ; y_{1}=m
$$

and yields some reservation utility to each owner $U_{\text {Res }}^{i}$, specified below. In this section we assume $A=1$, and normalize the aggregate endowment $\omega=1$ such that $k<1$. With these assumptions, the output of this technology is strictly inferior to the output of the partnership technology for the same level of investment. It may still be preferred by the minority shareholder if the investment decision of the controlling shareholders implies an unfavorable consumption profile over time. The production-exchange equilibrium with participation constraint is defined as before, but in addition the participation constraints of both owners are taken into account, such that owner 1's investment problem reads now:

$$
\begin{aligned}
& \max _{k} V^{1}(k) \quad \text { s.t. } \quad V^{i}(k) \geq U_{\text {Res }}^{i}, \quad i=1,2 \\
& c_{t}^{i} \geq 0, \quad i=1,2, \quad t=0,1 \\
& \text { plus budget constraints (2) and (3) }
\end{aligned}
$$

\subsubsection{Differences in initial endowments}

The goal in this section is to see how investment, share price and the after-trade ownership stake of each shareholder are affected by differences in owners' endowments of the consumption good and initial stakes, and how the outcome is influenced by the presence of the participation constraint.

\footnotetext{
${ }^{19}$ We have to exclude the possibility that it is in the interest of the controlling owner to operate the firm alone. For instance, suppose that some human capital inputs of both owners are necessary for the partnership firm. Alternatively, we could assume a minimum level of investment, which is needed to operate the firm.
} 
Using the expected utility function (4) and the budget constraints $c_{0}^{i}=\omega^{i}-m^{i}$ and $c_{1}^{i}=m^{i}$, we can specify the optimal amount of investment in the outside technology of each owner, $m=\frac{\delta}{1+\delta} \omega^{i}$. This implies a reservation utility $U_{\text {Res }}^{i}=\ln \left(\frac{1}{1+\delta} \omega^{i}\right)+\delta \ln \left(\frac{\delta}{1+\delta} \omega^{i}\right)$. We conduct a numerical analysis of the model with the following parameters: $\omega=1, A=1, \delta=0.99$ and $\alpha=0.5$. In the left graph of each of the following three figures, we let the the relative wealth of owner $1, \beta$, vary between 0 and 1 while the initial ownership stake $\bar{\theta}^{1}$ is fixed at 0.5 . In the right graph of each figure, we let $\bar{\theta}^{1}$ vary between 0.5 and 1 while $\beta$ is fixed at 0.5 . The solid lines correspond to the model with participation constraint, in particular to problem (17). The dotted lines represent the solution to the basic model with non-negativity constraints for consumption only, i.e. the solution to problem (6).
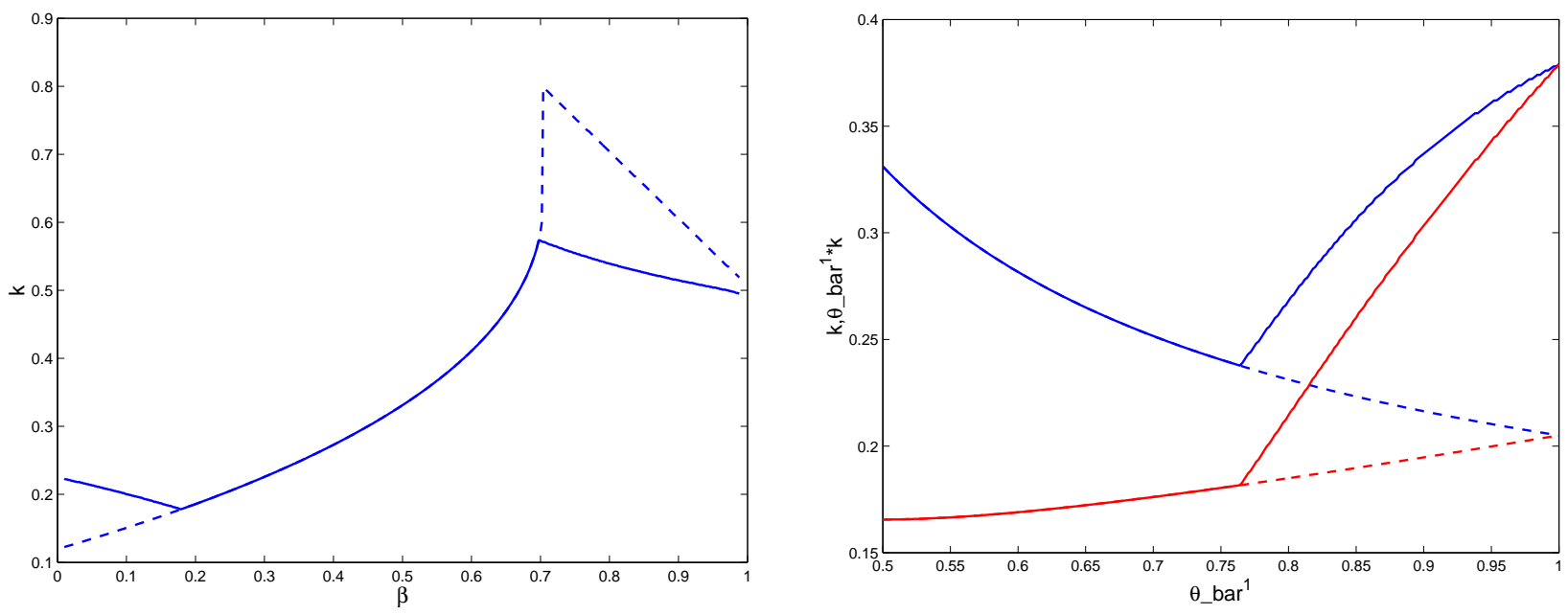

Figure 3: Left graph: Optimal investment $k$ as a function of owner 1's share of the endowment in the consumption good $\beta$ ( $\bar{\theta}^{1}$ is fixed to 0.5). Right graph: Optimal total investment $k$ (upper line) and individual investment expenditure of owner $1 \bar{\theta}^{1} k$ (lower line) as a function of owner 1's initial stake $\bar{\theta}^{1}$ ( $\beta$ is fixed to 0.5 ). The dotted lines are the solution problem without participation constraint.

Figure 3 shows the optimal level of investment in each case. At very low values of $\beta$, owner 1 would like to invest very small amounts. In this case, however, the richer owner 2 would prefer the outside option. Thus, the participation constraint of owner 2 imposes some minimum value of investment. At high values of $\beta$, some maximum value of $k$ is imposed - not only by the participation constraint of owner 2, but later on also from the non-negativity constraint for consumption at $t=1$ of owner 2 (he could not afford as high a level of investment as owner 1 would prefer). As for the effect of the initial share distribution, we mentioned in the discussion of Proposition 2 the two effects that are at work here. We see that the level of investment $k$ is decreasing with owner 1's initial stake since she has to put a higher fraction of investment this is the first and dominant effect. On the other hand, a higher stake gives extra revenue in the share trade that can be used for consumption and investment. We observe that individual 
investment expenditure of owner $1, \bar{\theta}^{1} k$, is increasing in the initial stake for most of its values. For high values of $\bar{\theta}^{1}$, the participation constraint of owner 2 is binding, and total investment has to go up in order to transfer a sufficient amount of wealth from date 0 to 1 for owner 2.
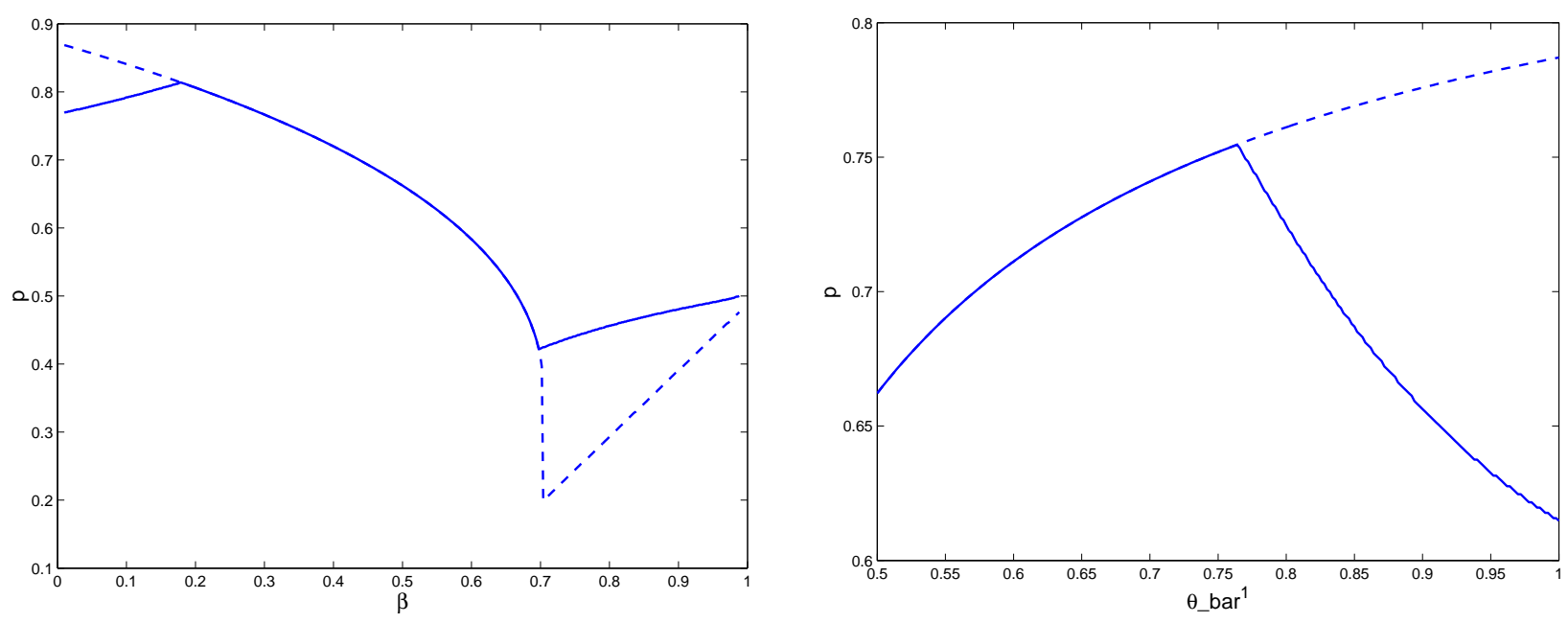

Figure 4: Equilibrium firm value $p$ as a function of owner 1's share of the endowment in the consumption good $\beta$ (left graph) and as a function of owner 1's initial stake $\bar{\theta}^{1}$ (right graph).

Figure 4 plots the firm value (the price of all shares). As stated in Proposition 2, the firm value is decreasing in the relative wealth position of the controlling owner. This relation is reversed at extreme values of $\beta$ since the investment decision is bound by the participation constraint of owner 2. At high initial stakes of owner 1, investment is increased due to the participation constraint, and the share price falls.
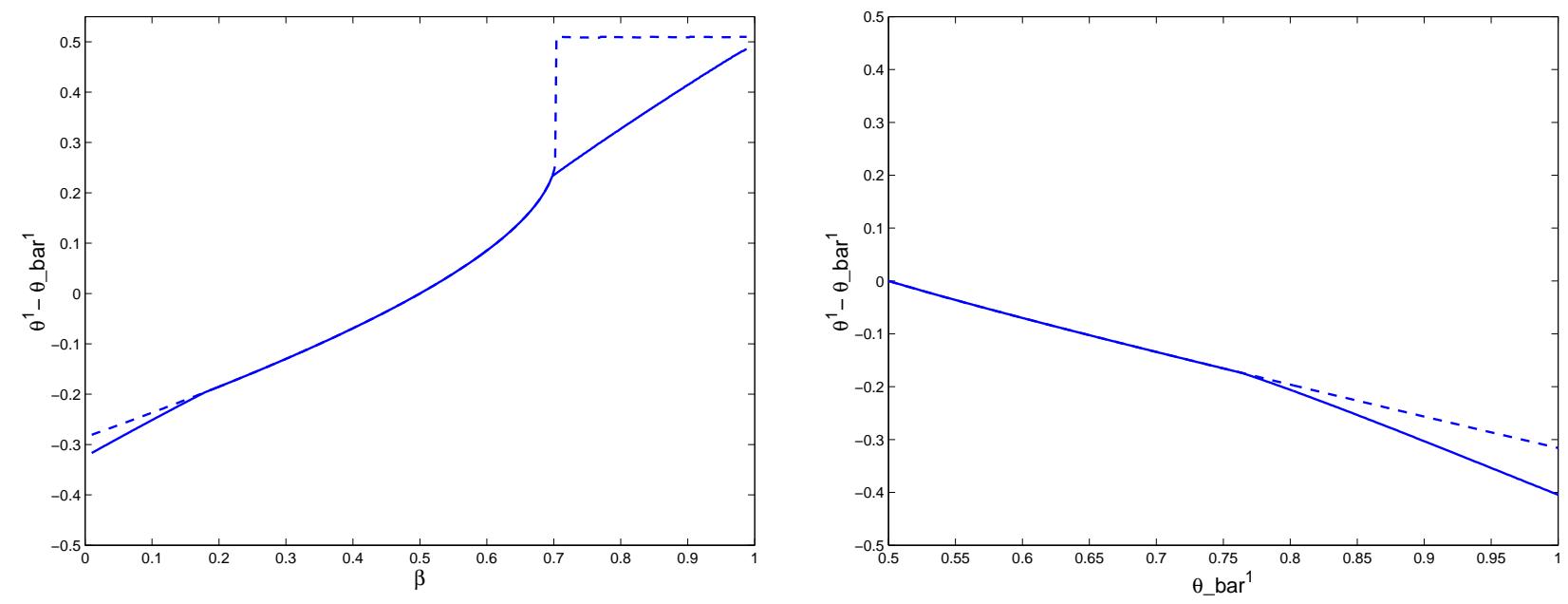

Figure 5: Equilibrium purchase of shares by owner $1\left(\theta^{1}-\bar{\theta}^{1}\right)$ as a function of owner 1's share of the endowment in the consumption good $\beta$ (left graph) and as a function of owner 1's initial stake $\bar{\theta}^{1}$ (right graph).

Finally, Figure 5 shows the net purchase of shares by owner 1. It illustrates the result in 
Proposition 1: the final stake of owner 1 should increase whenever her relative wealth $\beta$ is higher than her initial stake in the company $\bar{\theta}^{1}$ (note that the latter is fixed to 0.5 in the left graph of the figure). The participation constraint prevents owner 1 from acquiring the entire firm in the trading round if she is relatively rich. Also, it slows down the sale of shares by owner 1 if she holds high stake initially, but her relative wealth position is lower. That means that the participation constraint lowers the concentration of ownership as compared to the basic model whenever it binds. This is consistent with the empirical finding of La Porta et al. (1998) that investor protection and ownership concentration are negatively correlated, even after controlling for GNP per capita, GNP as a proxy for average firm size, and Gini coefficient of income. The authors' interpretation is that both mechanisms are substitutes in serving the purpose of controlling self-interested managers. In our model, however, it is the different endowments and preferences of shareholders that may lead to an increase of ownership concentration.

\subsubsection{Differences in preferences on intertemporal substitution and in endowments}

As we have seen in section 2.4, different utility functions of the two owners, in general, create disagreement on the preferred level of investment. In the numerical solution with equal endowments presented there, the differences of interest do not become so large as to make the participation constraint binding. Here we look at the interaction of different endowments in the consumption good and different preferences on intertemporal substitution. Appendix A.4 contains details of the calculations and the reservation utilities of both owners. The following two sets of graphs in Figure 6 present the case where $\beta=0.65$ (first row) and $\beta=0.35$ (second row). The initial stakes of both owners are 0.5 .

We see that with an unequal distribution of initial wealth, differences in preferences on intertemporal substitution have a larger effect on investment than under equal distribution (section 2.4). If the controlling owner is wealthier than the non-controlling owner, investment is increasing in $\gamma$ until the point where the participation constraint sets in. From the viewpoint of owner 2, investment is too high and would lead to an uneven distribution of consumption over the two dates. Therefore, owner 2 seeks to sell shares, which in turn increases the price. The controlling owner exploits this mechanism by setting $k$ even higher (the more the higher $\gamma$ ) - up to a point where this makes her own consumption profile too uneven or, in the presence of a participation constraint, where this constraints becomes binding. At this point, owner 2 is indifferent between investing in the partnership firm and his outside option.

If the controlling owner is less wealthier than the non-controlling owner, investment is again largest when both owners have the same preferences $(\gamma=1)$ and decreases for higher $\gamma$ until the participation constraint imposes some minimum investment. Owner 2 would prefer higher levels 

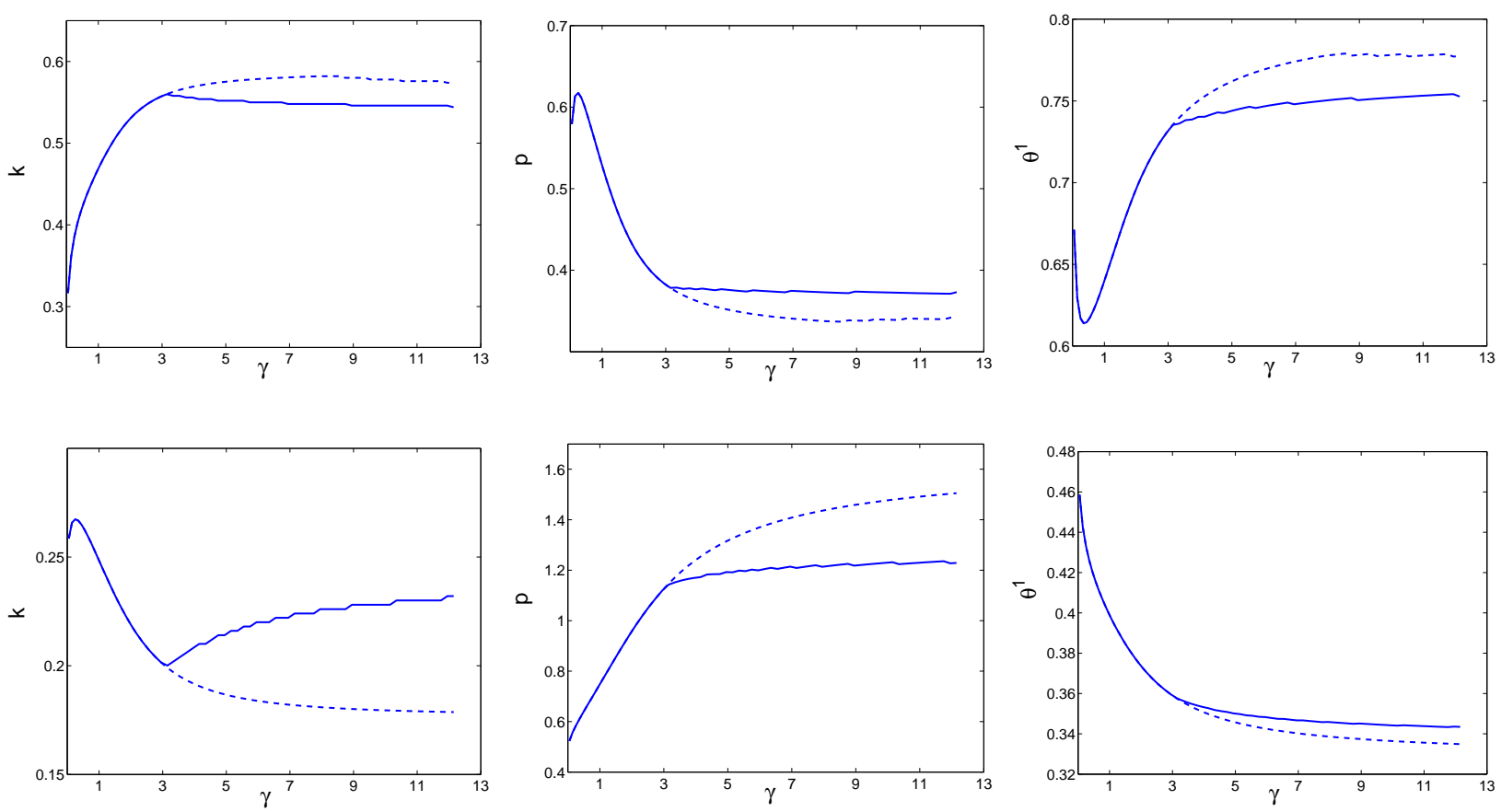

Figure 6: Optimal investment $k$, firm value $p$ and the ownership stake of owner 1, $\theta^{1}$ as functions of the value of $\gamma$ in the utility function of owner 2. First row of graphs: $\beta=0.65$, second row: $\beta=0.35$. In each case, $\bar{\theta}^{1}=0.5$. The dotted lines are the solution to the problem without participation constraint.

of investment whenever $\gamma>1$, but since he cannot influence the decision directly, he seeks to acquire shares, which in turn increases their price. Note that the presence of the participation constraint lowers the ex-post ownership concentration in both cases since it lowers the amount of shares that is acquired by the wealthier agent when $\gamma$ is high.

\subsection{Private benefits of control, one period}

In this section, we investigate the effects of private benefits of control on investment, firm value and after-trade ownership distribution in one-period models. While subsection 3.2.2 extends our basic one-period model to the presence of private benefits, we analyze a complete markets version of this model in subsection 3.2.1 to show that private benefits alone are enough to create disagreement on the investment policy among shareholders. The following section 3.3 extends the incomplete markets model with private benefits to two periods.

In this section, we assume that a fraction $\lambda \in[0,1]$ of the output (=profits) can be expropriated by the initial majority owner (owner 1 ), so that only the fraction $1-\lambda$ is distributed according to the after-trade ownership stakes. Private benefits are also considered in the dynamic model of ownership by Edelstein et al. (2005). ${ }^{20}$ In their model, a large shareholder who enjoys higher

\footnotetext{
${ }^{20}$ In the cited paper, private benefits of an additional share are allowed to vary in a continuous way with the
} 
private benefits of control holds a greater stake in the long run. In our model of incomplete markets, however, the initial controlling owner may hold a larger or smaller share at the final date of the model depending on her relative wealth and initial stake. In contrast to the monotonic nature of adjustment in Edelstein et al. (2005), the adjustment in the two-periods model does not have to be monotonic.

\subsubsection{Complete markets}

In this section, we make a digression to a setup with complete markets. Markets are completed by the possibility of unconstrained borrowing and lending from exogenous investors at the interest rate $r$. The version without private benefits just confirms the Fisher separation theorem, and is therefore confined to Appendix B. Here we show that the existence of private benefits is sufficient for the Fisher separation theorem to break down, even if markets are complete. We derive how investment depends on the magnitude of private benefits and the initial ownership stake of the controlling owner. As we do in Appendix B, we use a general utility function and a neoclassical production function $F(k)$ to demonstrate the results. Every owner can invest in firm shares and bonds. Individual bond-holdings are denoted by $b^{i}$. The budget constraints for the two owners and the two dates read

$$
\begin{aligned}
c_{0}^{i} & =\omega^{i}+\left(\bar{\theta}^{i}-\theta^{i}\right) p-\bar{\theta}^{i} k-b^{i}, \quad i=1,2 \\
c_{1}^{1} & =\left((1-\lambda) \theta^{1}+\lambda\right) F(k)+(1+r) b^{1} \\
c_{1}^{2} & =(1-\lambda) \theta^{2} F(k)+(1+r) b^{2}
\end{aligned}
$$

Similar to the results in Appendix B, a no-arbitrage condition for bonds and shares ${ }^{21}$ yields the firm value $p=\frac{(1-\lambda) F(k)}{1+r}$. Note that the value of the firm is reduced by the proportion $\lambda$ as compared to the result without private benefits in Appendix B. Individual asset holdings are not uniquely determined since the non-arbitrage price makes both assets, firm shares and bonds, equivalent.

By maximizing utility with respect to $k$ we obtain the rules for the preferred investment levels for the two owners:

$$
\begin{aligned}
F^{\prime}\left(k^{(1)}\right) & =\frac{\bar{\theta}^{1}(1+r)}{\bar{\theta}^{1}(1-\lambda)+\lambda} \\
F^{\prime}\left(k^{(2)}\right) & =\frac{1+r}{1-\lambda}
\end{aligned}
$$

ownership stake while we restrict them to be constant, except at the stake of $50 \%$ where they switch from zero to $\lambda$.

\footnotetext{
${ }^{21}$ We use the first-order conditions with respect to $\theta^{i}$ and $b^{i}$.
} 
We see that in this case shareholders do not agree on the amount of investment. Furthermore, the preferred level of investment of the controlling shareholder does not maximize the net value of the firm $(p-k)$. Private benefits create an externality between the firm and its shareholders ${ }^{22}$, and therefore the Fisher separation theorem is not valid any more. In the following proposition, we provide comparative statics results for the level of investment.

Proposition 3. Suppose that the controlling owner receives private benefits of control and that markets are complete. Then

(i) the preferred level of investment of the controlling owner, $k^{(1)}$, and therefore the level of investment under majority voting, is increasing in the proportion of private benefits of output $\lambda$, while the preferred level of investment of the non-controlling owner, $k^{(2)}$, is decreasing in $\lambda$;

(ii) the preferred level of investment of the controlling owner, $k^{(1)}$, depends negatively on her initial ownership stake $\bar{\theta}^{1}$, while the preferred level of investment of the non-controlling owner does not depend on his initial ownership stake.

\section{Proof. See Appendix A.5.}

Higher private benefits give higher dividends to the controlling owner for the same amount of investment. This leads her to invest more since only returns are important in the investment decision, and the optimal consumption profile can be achieved by bond trading. The opposite is true for the non-controlling owner. As a consequence, the preferred level of investment of the owner with private benefits, $k^{(1)}$, is larger than the investment in the case without private benefits, and the preferred level of investment of the non-controlling owner, $k^{(2)}$, is smaller. ${ }^{23}$ As for part (ii), an additional share decreases the level investment since it lowers the return: it increases the dividends to be paid to this owner relatively less than the amount of initial investment since the fraction $\lambda$ of output received as private benefits stays constant. No such effect is present for the non-controlling owner.

\subsubsection{Incomplete markets}

After this digression to the complete markets model, we come back to our basic model of incomplete markets with log utility and Cobb-Douglas production function, and augment it by private benefits of control. We analyze the effect of private benefits on investment and share trade. The budget

\footnotetext{
${ }^{22}$ See Kelsey and Milne (2006) for a general model of the firm with externalities.

${ }^{23}$ The investment rule for the complete markets model without private benefits of control is given in equation (63).
} 
constraints are now as follows:

$$
\begin{aligned}
c_{0}^{i} & =\omega^{i}+\left(\bar{\theta}^{i}-\theta^{i}\right) p-\bar{\theta}^{i} k, \quad i=1,2 \\
c_{1}^{1} & =\left((1-\lambda) \theta^{1}+\lambda\right) A k^{\alpha} \\
c_{1}^{2} & =(1-\lambda) \theta^{2} A k^{\alpha}
\end{aligned}
$$

The equilibrium definitions are the same as in the basic model (see Section 2.2). The steps needed to obtain the following exchange equilibrium are similar to the ones for the basic model outlined in Appendix A.1. The market-clearing price of the firm and ownership stakes, all as functions of the level of investment, are given by the following expressions

$$
\begin{aligned}
p(k) & =\delta(1-\lambda)(\omega-k) \\
\theta^{1}(k) & =\frac{\beta \omega+\left(\delta \bar{\theta}^{1}(1-\lambda)-\lambda\right)(\omega-k)-\bar{\theta}^{1} k}{(1+\delta)(1-\lambda)(\omega-k)} \\
\theta^{2}(k) & =\frac{(1-\beta) \omega+\delta \bar{\theta}^{2}(1-\lambda)(\omega-k)-\bar{\theta}^{2} k}{(1+\delta)(1-\lambda)(\omega-k)}
\end{aligned}
$$

In the following proposition we give some sufficient conditions when the owners will sell or acquire shares in the trading stage.

Proposition 4. The controlling owner sells shares if her relative wealth is smaller than or equal to her initial ownership stake $\left(\beta \leq \bar{\theta}^{1}\right)$. A sufficient condition for the controlling owner to acquire shares is $\beta>\bar{\theta}^{1}(1-\lambda)+\lambda$. Necessary conditions for the direction of share trade are given in Appendix A.6.

\section{Proof. See Appendix A.6.}

In contrast to the basic model, now there is share trade in the case of proportional endowments $\left(\beta=\bar{\theta}^{1}\right)$. The controlling owner sells some of her shares since this allows her to consume a part of the private benefits already at time $t=0$. Since the model ends at time $t=1$, there is no need to maintain the majority in order to have access to private benefits in the future. One could add arbitrarily many trading periods between the time of investment and the time where the dividends are paid out. In the case of proportional endowments, owner 1 would then gradually reduce her stake over all trading periods.

Next, we characterize the production-exchange equilibrium. Interior solutions are given by the following expression. As in the basic model, the first-order condition for $k$ of owner 1 takes the form of a quadratic equation.

$$
k=\left(-\frac{P_{\lambda}}{2}-\sqrt{\frac{P_{\lambda}^{2}}{4}-Q_{\lambda}}\right) \omega
$$


where

$$
\begin{aligned}
P_{\lambda} & =\frac{(1-\alpha) \delta \beta-\delta(1+2 \alpha \delta)\left[(1-\lambda) \bar{\theta}^{1}-\lambda\right]+[1+\delta(1+\alpha)] \bar{\theta}^{1}}{(1+\alpha \delta)\left[(1+\delta) \bar{\theta}^{1}+\delta \lambda\left(1-\bar{\theta}^{1}\right)\right]} \\
Q_{\lambda} & =\frac{\alpha \delta\left[\beta+\delta\left((1-\lambda) \bar{\theta}^{1}+\lambda\right)\right]}{(1+\alpha \delta)\left[(1+\delta) \bar{\theta}^{1}+\delta \lambda\left(1-\bar{\theta}^{1}\right)\right]}
\end{aligned}
$$

The following proposition addresses the question how the presence and magnitude of private benefits of control affects the level of investment at interior solutions.

Proposition 5. If the controlling shareholder is able to extract private benefits of control, a higher fraction of private benefits $\lambda$ increases (decreases) the amount of investment if her initial stake exceeds (falls below) her relative wealth, i.e. if $\bar{\theta}^{1}>\beta\left(\bar{\theta}^{1}<\beta\right)$. In the case of proportional endowments, $\bar{\theta}^{1}=\beta$, private benefits do not affect the level of investment.

\section{Proof. See Appendix A.7.}

Consider the case where $\bar{\theta}^{1}>\beta$. Here, a higher fraction of private benefits $\lambda$ leads to more investment. On the one hand, this enables the controlling agent to extract more private benefits since she gets a larger part of the output. On the other hand, a higher $\lambda$ lowers the share price. ${ }^{24}$ Consumption smoothing is achieved by selling more shares in response to a higher $\lambda .{ }^{25}$ So a reduced share price is bad for owner 1 but the first effect, more private benefits, dominates, and the level of investment increases. The other cases may be explained similarly by the interplay of these effects.

\subsection{Private benefits of control, two periods}

Most of the existing models of the firm with incomplete markets and collective decision-making on production cited in the introduction are one-period models. One exception is the generalized model in Grossman and Hart (1979) with many time periods but only one production decision at date 1 that is binding for all future periods. We will analyze our model with private benefits for two periods (three dates) with a decision on investment at the beginning of each period. The investment decision in the second period depends on the (endogenously determined) ownership stakes after the first round of trade. One of the difficulties with multi-period models is that this investment function may be discontinuous - for example at 0.5 if a majority rule is assumed. As Grossman and Hart (1979) note, there may also arise a conflict between present and future shareholders if production plans can be reversed later. We circumvent this problem by assuming that capital fully depreciates in one period.

\footnotetext{
${ }^{24}$ Note that $\frac{\partial p(k)}{\partial \lambda}=-\delta\left(\omega-k+(1-\lambda) \frac{\partial k}{\partial \lambda}\right)$. This is unambiguously negative if $\bar{\theta}^{1}>\beta$.

${ }^{25}$ The effect on the final stake of owner 1 of an increase in $\lambda$ is negative for $\bar{\theta}^{1} \geq \beta$, but may become positive for large $\beta$. See Appendix A.8 for details.
} 
When we extend our basic model without private benefits to two periods and assume exogenous endowments only at the initial date, there is no further need to trade after the first period. Both the payoffs and the new investment would be split among the owners according to the ownership stakes after the first round of trade. This amounts to the case of proportional endowments, and we have shown in the basic one-period model that there is no share trade in this case. In contrast, with private benefits of control, there are incentives to trade if relative wealth and ownership stake coincide. So it is interesting to analyze this model for two periods since we are likely to see share trade in both periods. The following figure depicts the timing of the two-period model.

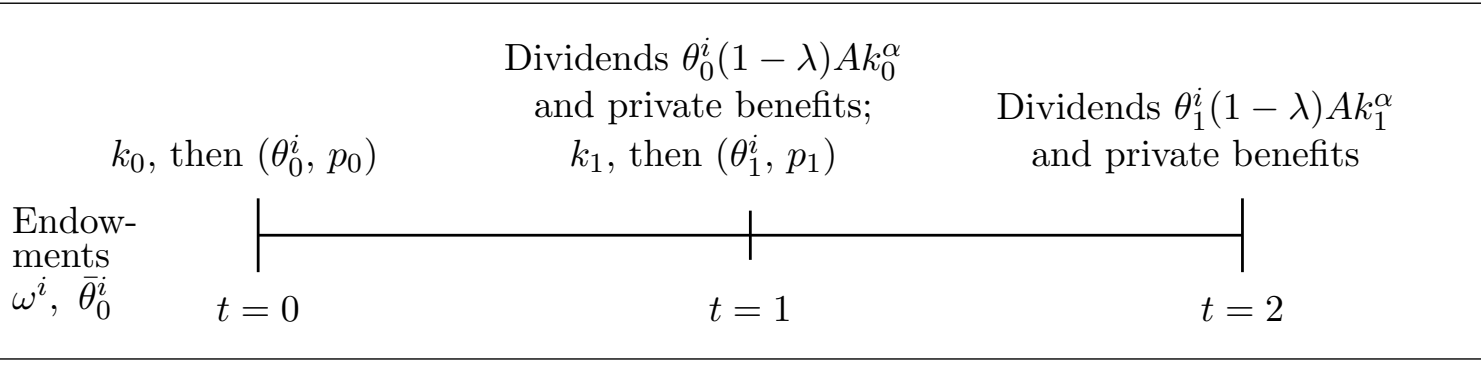

Figure 7: Time line of the two-period model with private benefits

Owners receive an exogenous endowment in the first period only. As before, we assume without loss of generality that owner 1 holds a majority initially. Therefore, she has decision power on the level of investment $k_{0}$, and receives the private benefits after the first period. Both owners receive dividends at dates $t=1$ and $t=2$. The budget constraints are the following:

$$
\begin{aligned}
c_{0}^{i} & =\omega^{i}+\left(\bar{\theta}_{0}^{i}-\theta_{0}^{i}\right) p_{0}-\bar{\theta}_{0}^{i} k_{0}, i=1,2 \\
c_{1}^{1} & =\left((1-\lambda) \theta_{0}^{1}+\lambda\right) A k_{0}^{\alpha}+\left(\theta_{0}^{1}-\theta_{1}^{1}\right) p_{1}-\theta_{0}^{1} k_{1} \\
c_{1}^{2} & =(1-\lambda) \theta_{0}^{2} A k_{0}^{\alpha}+\left(\theta_{0}^{2}-\theta_{1}^{2}\right) p_{1}-\theta_{0}^{2} k_{1} \\
c_{2}^{1} & =\left((1-\lambda) \theta_{1}^{1}+\tilde{\lambda}^{1}\right) A k_{1}^{\alpha} \\
c_{2}^{2} & =\left((1-\lambda) \theta_{1}^{2}+\tilde{\lambda}^{2}\right) A k_{1}^{\alpha}
\end{aligned}
$$

The distribution of private benefits at $t=2$ and the power to make a decision on the level of investment $k_{1}$ are endogenously determined in the model. We need to make assumptions on the rules according to which private benefits at $t=2$ are distributed, i.e. we need to specify $\tilde{\lambda}^{i}, i=1,2$ in equations (24) and (25). We distinguish the following four cases:

- Case A ("Non-transferable control"): The control over the investment decision and private benefits always accrue to the initial majority owner no matter what the ownership distribution after the first round of trade is. Thus, the extra payment to owner $1, \tilde{\lambda}^{1}$, is assumed to 
be equal to $\lambda$, and $\tilde{\lambda}^{2}=0$. Owner 1 can be thought as a founder family with informational advantages or authority to keep private benefits and control even after selling out a majority stake.

- Case B ("Partial control"): The decision power on $k_{1}$ goes to the majority owner after the first round of share trade, but private benefits stay always with owner 1 (the original majority owner). Again, we have $\tilde{\lambda}^{1}=\lambda$ and $\tilde{\lambda}^{2}=0$.

- Case C ("Full control via majority"): Both decision power on $k_{1}$ and private benefits in the second period are transferred to the new majority owner. That is, holding a majority assures full control over the firm. Thus, we have

$$
\begin{aligned}
& \tilde{\lambda}^{1}=\mathbf{I}\left(\theta_{0}^{1} \geq 0.5\right) \lambda \\
& \tilde{\lambda}^{2}=\left(1-\mathbf{I}\left(\theta_{0}^{1} \geq 0.5\right)\right) \lambda
\end{aligned}
$$

where $\mathbf{I}($.$) is the indicator function.$

- Case D ("No private benefits"): There are no private benefits, i.e. $\tilde{\lambda}^{1}=\tilde{\lambda}^{2}=\lambda=0$. This case is a simple extension of the one-period basic model, and we include it for comparison.

This distinction of four different cases allows us to infer how the existence of private benefits, the possibility to become the controlling owner and the possibility to extract private benefits by the majority owner change the decisions on investment and share trading of the owners, as well as the share price.

The expected utility function is

$$
U^{i}=\ln c_{0}^{i}+\delta \ln c_{1}^{i}+\delta^{2} \ln c_{2}^{i}
$$

The equilibrium definitions of the basic model apply at each of the two periods. We restrict our attention to interior solutions where non-negativity constraints for consumption do not bind. The solutions are calculated backwards in time, taking previously determined variables as given. In other words, we derive time-consistent solutions, hence assuming that owners cannot commit to particular trading or investment strategies. The decision on investment depends on whether owner 1 or 2 hold a majority after the first round of trade. That means that the owners have to anticipate the identity of the new majority owner already in their demand for shares at $t=0$. All details of the solution are given in Appendix A.9.

We now report the numerical findings for the four cases. We fix the initial stake of each owner at 50 per cent, and show the results for investment, share trade and firm value in both periods for different values of $\beta$, the relative (initial) wealth of owner 1 . The proportion of output extracted 
as private benefits $\lambda$ is 0.1 . The other parameter values used for the calculations are $A=1, \omega=1$, $\delta=0.99$ and $\alpha=0.35 .{ }^{26}$ Figure 8 shows the results for investment at dates $t=0$ (left) and $t=1$ (right).
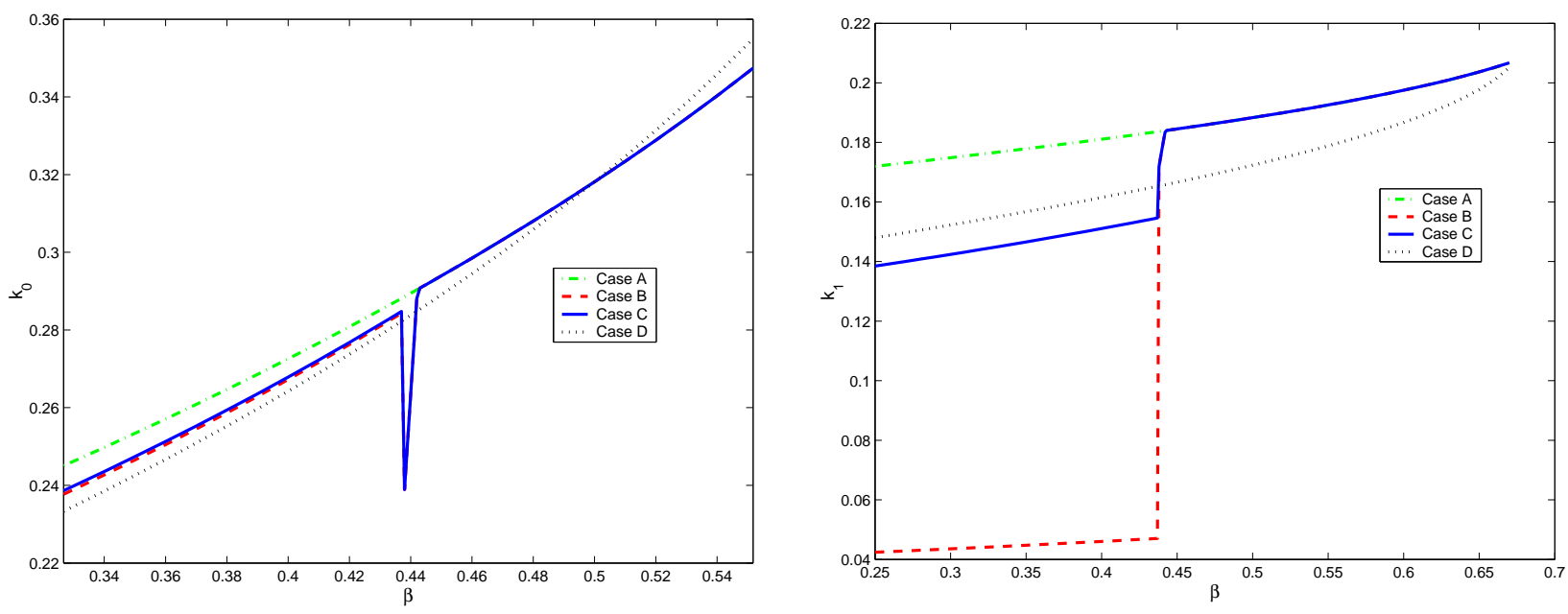

Figure 8: Left graph: Optimal level investment $k_{0}$ as a function of owner 1's share of the initial endowment in the consumption good $\beta$. The initial ownership stake $\bar{\theta}_{0}^{1}$ is fixed to 0.5. Right graph: Similarly, the optimal level of investment $k_{1}$.

Just as in the basic model, investment $k_{0}$ is overall increasing in the relative wealth of the (initial) controlling owner. ${ }^{27}$ This also carries over to $k_{1}$ since a higher $k_{0}$ implies more output, part of which can be invested at time $t=1$. All cases that involve private benefits (A, B and C) are identical if the initial majority owner keeps the majority after the first round of trade. ${ }^{28}$ That happens in our example for values of $\beta$ of approximately 0.45 and higher. For lower values of $\beta$, investment depends on our assumptions on the allocation of control and private benefits when owner 2 acquires a majority stake in the firm. Furthermore, the numerical solution for $k_{0}$ (left chart) confirms the finding of Proposition 5 for the one-period model: The presence of private benefits increases investment if $\beta<\bar{\theta}_{0}^{1}$ ( $=0.5$ in our example), and decreases it for the opposite case. $^{29}$

In cases $\mathrm{B}$ and $\mathrm{C}$, where owner 1 may loose the control over the firm, we observe some strategic behavior of owner 1 for values of $\beta$ close to the point where the control transfer takes place (at 0.44 approximately). In order to keep the control over the investment decision at $t=1$, she "manipulates", i.e. drastically reduces, the level of investment at $t=0$. Consider also the left chart of Figure 9, which depicts the ownership stake of owner 1 after the first round of trading,

\footnotetext{
${ }^{26}$ With $\alpha=0.5$, as we fixed it in the previous sections, the results are qualitatively the same. However, the changes in investment around the point where control is transferred from owner 1 to owner 2 are less pronounced.

${ }^{27} \mathrm{An}$ exception is the downward spike in cases $\mathrm{B}$ and $\mathrm{C}$ around $\beta=0.44$ that we shall discuss shortly.

${ }^{28}$ Recall that the owners can perfectly anticipate whether the identity of the majority owners changes or not.

${ }^{29}$ Again, the only exception is the downward spike in cases B and C.
} 
$\theta_{0}^{1}$. One can see that owner 1 's ownership stake $\theta_{0}^{1}$ jumps to exactly 50 per cent at the point when investment jumps downwards.
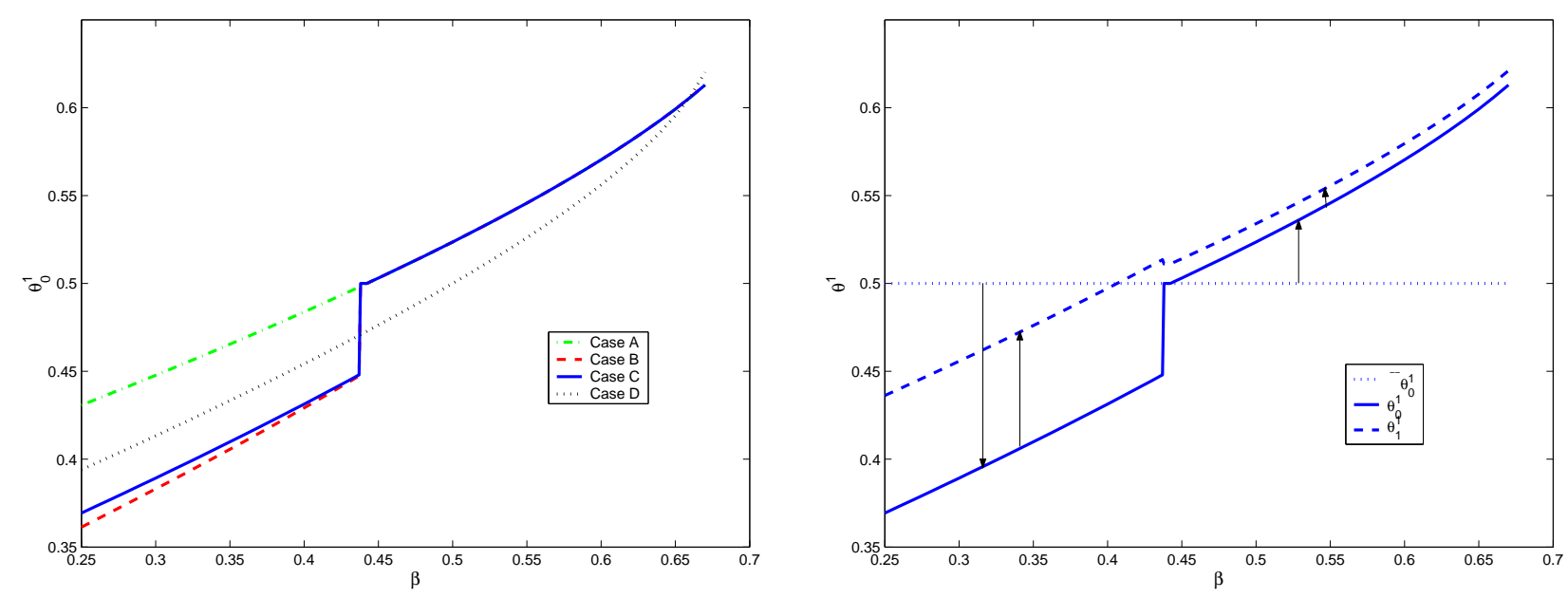

Figure 9: Left graph: Ownership stake $\theta_{0}^{1}$ as a function of owner 1's share of the initial endowment in the consumption good $\beta$. The initial ownership stake $\bar{\theta}_{0}^{1}$ is fixed to 0.5. Right graph: Evolution of the ownership stake of owner 1 for case $C$.

Note that at the point where control is transferred to owner 2 in cases B and C, also investment $k_{1}$ changes sharply (right chart of Figure 8 ). The reason is that both owners maximize different objective functions when they decide on investment. In contrast, in case A, owner 1 continues to control the firm no matter what the ownership distribution is, and in case D owners are unanimous about the level of investment $k_{1}$ (see the analytical solution in Appendix A.9). If owner 2 acquires a majority stake, the level of investment $k_{1}$ is higher in cases $\mathrm{C}$ and $\mathrm{A}$ than in case $\mathrm{B}$, since in the former private benefits and control over investment are concentrated in one hand. Recall that in case B control is transferred to owner 2, while private benefits still accrue to owner 1 . This misalignment of control and private benefits is obviously bad for investment. Furthermore, $k_{1}$ is higher in case $\mathrm{A}$ than in $\mathrm{C}$ since the decision over investment is made by the owner with a smaller share..$^{30}$

Turning to the ownership dynamics, we have the following analytical result:

Proposition 6. In cases $\mathrm{A}, \mathrm{B}$ and $\mathrm{C}$ where private benefits are non-zero, the initial majority owner increases her stake in the second round of trade.

Proof. See Appendix A.9.

This effect is a pure wealth effect. The controlling owner disposes of a relative wealth that is by the fraction of private benefits $\lambda$ higher than her ownership stake at time $t=1$. Therefore she

\footnotetext{
${ }^{30}$ This owner needs a higher investment to generate the same dividend for herself. See Proposition 2 for a discussion of this comparative statics result in the basic model.
} 
always acquires shares.

In the right graph of Figure 9, we pick case $\mathrm{C}$ and show the evolution of the ownership stake of initial controlling owner from the initial stake $\bar{\theta}_{0}^{1}$, over the stake after the first round of trade $\theta_{0}^{1}$ to the final stake after the second round of trade $\theta_{1}^{1}$, as indicated by the arrows.

The important result we observe is an accumulation of shares in the hands of the initial controlling owner 1 over both periods, even for levels of relative wealth equal to the initial stake or slightly lower (down to $\beta=0.45$ in our example). ${ }^{31}$ This result is different from the oneperiod model with private benefits (section 3.2.2), where the ownership stake of the owner with private benefits decreases in the case of proportional endowments $\left(\beta=\bar{\theta}_{0}^{1}\right)$. This result of an increase in the ownership stake in the hands of the owner with private benefits of control can be related to the observed increase in managerial ownership in post-privatization enterprises in Central and Eastern Europe. ${ }^{32}$ If we believe the amounting anecdotal evidence that managers and their affiliates were able to extract private benefits of control, then our two-period model correctly predicts the increase in managerial ownership. To obtain this result it is not necessary to assume that managers are the wealthier shareholders right after privatization - the private benefits alone allow them to accumulate shares over time.
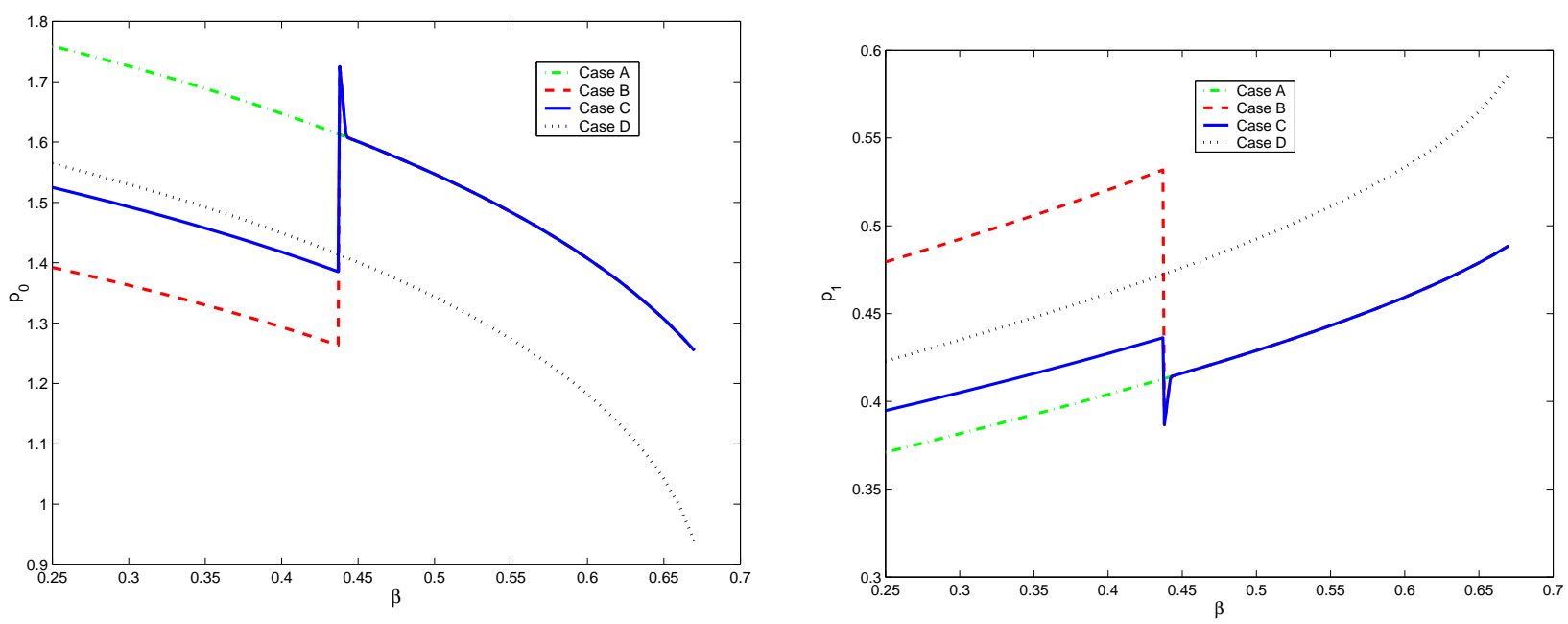

Figure 10: Left graph: Firm value $p_{0}$ as a function of owner 1's share of the initial endowment in the consumption good $\beta$. The initial ownership stake $\bar{\theta}_{0}^{1}$ is fixed to 0.5. Right graph: similarly, the firm value $p_{1}$.

Figure 10 shows the results for the firm value $p$ at date $t=0$ (left) and date $t=1$ (right). At the continuous parts of the curve, $p_{0}$ is decreasing in $\beta$. As in the one-period model, investment is increasing in $\beta$, and the share price is a decreasing function of investment. (With a higher investment, an owner needs less shares to smooth consumption.) The price in the second trading

\footnotetext{
${ }^{31}$ For higher values of $\lambda$ this threshold would be even lower.

${ }^{32}$ See for example Chapter ?? of this Thesis for data on Russian firms.
} 
round $p_{1}$ is increasing since a higher $\beta$ implies more investment $k_{0}$ and thus higher output at time $t=1$, so owners dispose of more resources to acquire shares. Near to the point where control is transferred (cases B and C), the price "jumps" upwards at $t=0$ and downwards at $t=1$. We now see why owner 1 strategically lowers investment $k_{0}$ when she wants to keep control over the firm. Lower investment $k_{0}$ increases the share price and makes it therefore more difficult for owner 2 to acquire shares. The price $p_{1}$ jumps downward since the reduced investment $k_{0}$ makes that there are less resources at $t=1$ to acquire shares.

From a normative point of view, which of the corporate governance arrangements in the presence of private benefits - case A, B or C - would be preferred by the owners? Our numerical simulations indicate that both cases $\mathrm{A}$ and $\mathrm{C}$ (non-transferable control and full control via majority ownership) are Pareto-superior to cases B (partial control). The low investment levels when there is a misalignment of control over investment and private benefits make this the least preferred option. It depends however on the initial stake and the distribution of relative wealth whether control should better stay in the hands of a powerful family (case A) or should be transferred to the majority owner (case $\mathrm{C}$ ) according to the Pareto criterion. ${ }^{33}$

\section{Conclusion}

In this paper, we have analyzed a general equilibrium model with one firm, two owners and an incomplete markets structure (i.e. lending and borrowing are impossible). Under these assumptions, there is no unanimity between shareholders about the amount of investment. We assume that the investment decision is made by the majority owner. We have studied the effects of different wealth, initial stakes and disposition to substitute consumption between periods among shareholders on three outcomes: the amount of investment, the firm value and after-trade ownership stakes. When we extend the basic model by introducing private benefits of control, interesting dynamics of ownership arise. In particular, increasing stakes of controlling shareholders, as observed in Eastern European countries after privatization, can be rationalized in this model.

In future research, the model can be extended in several dimensions. In a model with aggregate and idiosyncratic uncertainty, we could study how shocks to productivity or individual endowments (or labor supply) affect investment, firm value and share trade. A model with more than two (and more than two types of) owners, coalition building among shareholders becomes important. Furthermore, pricing mechanisms other than the competitive Walrasian mechanism in this paper can be introduced. It is likely that a large shareholder who faces a continuum of small shareholders can influence the share price. Finally, more than one firm in the model would

\footnotetext{
${ }^{33}$ When both solutions are different - for lower values of $\beta$ where the majority goes to owner 2 - owner 1 is always better off in case $\mathrm{A}$, but owner 2 may be better off in case $\mathrm{C}$ or in case $\mathrm{A}$.
} 
imply that owners have to determine their demand for shares in each firm by optimal portfolio considerations. It would then be interesting to derive and to test hypotheses about the relation between the composition of the shareholder base of a firm on the one hand and investment, firm value and share trade on the other hand. We believe that the model of this paper and possible extensions contribute to highlight the importance of ownership arrangements for real economic outcomes.

\section{Appendix}

\section{A Proofs and details of calculations}

\section{A.1 Exchange equilibrium in the basic model}

We prove expressions (7) -(9). The first-order condition of (5) with respect to $\theta^{i}$ is

$$
\frac{-p}{\omega^{i}+\left(\bar{\theta}^{i}-\theta^{i}\right) p-\bar{\theta}^{i} k}+\frac{\delta}{\theta^{i}}=0
$$

Note that the second-order condition for a maximum is satisfied. Solving for $\theta^{i}$ yields the ownership stake as a function of the price of the firm $p$ and investment $k$ :

$$
\theta^{i}(k, p)=\frac{\delta\left(\omega^{i}+\bar{\theta}^{i}(p-k)\right)}{(1+\delta) p}
$$

The market clearing condition $\theta^{1}+\theta^{2}=1$ yields equation ( 7 ) for the price, and substituting into (28) we get (9) and the equivalent expression (8).

\section{A.2 Production-exchange equilibrium in the basic model}

The first-order condition of the indirect utility function (11) reads

$$
\frac{\partial V^{1}}{\partial k}=-\frac{\delta\left(\bar{\theta}^{1}-\theta^{1}\right)+\bar{\theta}^{1}}{\beta \omega+\left(\bar{\theta}^{1}-\theta^{1}\right) p-\bar{\theta}^{1} k}+\frac{\delta \alpha}{k}=0
$$

Note that we skipped all derivatives of the ownership stake $\theta^{i}$ with respect to $k$ since they cancel out due to the first-order condition for the optimal stake (envelope theorem). Multiplying by $k$ and $c_{0}^{1}$ and rearranging terms leads to the quadratic equation

$$
0=k^{2}+P \omega k+Q \omega^{2}
$$

where $P$ and $Q$ are given in equations (13) and (14). To see which of the two solutions is the maximum, note first that the derivative of the right hand side of (30) with respect to $k$ has the same sign as the derivative of (29), which is the second derivative of the indirect utility function 
(11). For a maximum we need that this derivative is negative, i.e. $2 k+P \omega<0$ or $k<-\frac{P}{2} \omega$. Consequently, (12) is the optimal interior solution.

Next, we find the corner solution for $k$ when some non-negativity constraint for consumption is binding. Suppose that the constraint $c_{0}^{2} \geq 0$ is binding. Using the budget constraint (2) for $i=2$ and then expressions (7) and (10), we get

$$
\begin{aligned}
c_{0}^{i} & =(1-\beta) \omega+\left(\theta^{1}-\bar{\theta}^{1}\right) p-\left(1-\bar{\theta}^{1}\right) k \\
& =\frac{1}{1+\delta}\left[(1+\delta-\beta) \omega-\left(1+\delta-\bar{\theta}^{1}\right) k\right]
\end{aligned}
$$

Equalizing to zero gives the level of investment

$$
k=\frac{1+\delta-\beta}{1+\delta-\bar{\theta}^{1}}
$$

Using (10), this yields an after-trade ownership stake of owner 1

$$
\begin{aligned}
\theta^{1}(k) & =\bar{\theta}^{1}+\frac{\left(\beta-\bar{\theta}^{1}\right) \omega}{(1+\delta)\left(\omega-\frac{1+\delta-\beta}{1+\delta-\bar{\theta}^{1}}\right)} \\
& =\bar{\theta}^{1}+\frac{\left(\beta-\bar{\theta}^{1}\right) \omega\left(1+\delta-\bar{\theta}^{1}\right)}{(1+\delta)\left(\beta-\bar{\theta}^{1}\right) \omega} \\
& =1+\frac{\delta}{1+\delta} \bar{\theta}^{1}
\end{aligned}
$$

This would imply a negative stake of owner 2 . The constraint $c_{1}^{2}=\theta^{2} A k^{\alpha} \geq 0$ however requires that $\theta^{2} \geq 0$ (or $\theta^{1} \leq 1$ ) since $A, k$ and $\alpha$ are all positive numbers. Now, setting $\theta^{1}(k)=1$ and using (10), we get the corner solution for the level of investment given in equation (15).

\section{A.3 Proof of Proposition 2}

Part (i): In order to see how $k$, given in equation (12) changes with $\beta$ and $\bar{\theta}^{1}$, we calculate first the derivatives of $P$ and $Q$ :

$$
\begin{aligned}
\frac{\partial P}{\partial \beta} & =\frac{1-\alpha}{(1+\delta)\left(\delta^{-1}+\alpha\right) \bar{\theta}^{1}}>0 \\
\frac{\partial Q}{\partial \beta} & =\frac{\alpha}{(1+\delta)\left(\delta^{-1}+\alpha\right) \bar{\theta}^{1}}>0 \\
\frac{\partial P}{\partial \bar{\theta}^{1}} & =-\frac{(1-\alpha) \beta}{(1+\delta)\left(\delta^{-1}+\alpha\right)\left(\bar{\theta}^{1}\right)^{2}}<0 \\
\frac{\partial Q}{\partial \bar{\theta}^{1}} & =-\frac{\alpha \beta}{(1+\delta)\left(\delta^{-1}+\alpha\right)\left(\bar{\theta}^{1}\right)^{2}}<0
\end{aligned}
$$

Next, we prove that $P$ is a negative number. From (13),

$$
P=\frac{(1-\alpha) \beta-(1+2 \delta)\left(\delta^{-1}+\alpha\right) \bar{\theta}^{1}}{(1+\delta)\left(\delta^{-1}+\alpha\right) \bar{\theta}^{1}}<0
$$


Note that the denominator is positive, and the numerator is negative since by assumption $\bar{\theta}^{1} \geq 0.5$, $\alpha \in(0,1)$ and $\beta \in[0,1]$. Now we calculate from equation (12) the derivative of $k$ with respect to $\beta$ :

$$
\frac{\partial k}{\partial \beta}=[-\frac{1}{2} \underbrace{\frac{\partial P}{\partial \beta}}_{>0}-\frac{1}{2}\left(\frac{P^{2}}{4}-Q\right)^{-\frac{1}{2}}(\underbrace{\frac{1}{2} \underbrace{\frac{\partial P}{\partial \beta}}_{>0}}_{<0}-\underbrace{\frac{\partial Q}{\partial \beta}}_{>Q})] \omega
$$

In order to prove that $\frac{\partial k}{\partial \beta}>0$, one can see from (35) that it suffices to show that $\frac{1}{2}\left(\frac{P^{2}}{4}-Q\right)^{-\frac{1}{2}} P<-1$. Multiplying by $-2 \sqrt{\frac{P^{2}}{4}-Q}$ yields

$$
\begin{aligned}
2 \sqrt{\frac{P^{2}}{4}-Q} & <-P \\
4\left(\frac{P^{2}}{4}-Q\right) & <P^{2} \\
Q & >0
\end{aligned}
$$

Taking squares without changing the inequality sign is possible since we have positive numbers on both sides. It can be verified easily that $Q$, given in equation (14), is indeed a positive number.

With respect to the initial ownership stake, we have the following derivative:

$$
\frac{\partial k}{\partial \bar{\theta}^{1}}=[-\frac{1}{2} \underbrace{\frac{\partial P}{\partial \bar{\theta}^{1}}}_{<0}-\frac{1}{2}\left(\frac{P^{2}}{4}-Q\right)^{-\frac{1}{2}}(\frac{1}{2} \underbrace{P \frac{\partial P}{\partial \bar{\theta}^{1}}}_{>0}-\underbrace{\frac{\partial Q}{\partial \bar{\theta}^{1}}}_{<0})] \omega
$$

By the same argument as before, the second term has more weight than the first term, such that the whole expression becomes negative.

Part (ii): Since $p$ is a function of $k$, part (ii) follows directly from part (i) and equation (7):

$$
\begin{aligned}
& \frac{\partial p(k)}{\partial \beta}=\frac{\partial p(k)}{\partial k} \frac{\partial k}{\partial \beta}=-\delta \frac{\partial k}{\partial \beta}<0 \\
& \frac{\partial p(k)}{\partial \bar{\theta}^{1}}=\frac{\partial p(k)}{\partial k} \frac{\partial k}{\partial \bar{\theta}^{1}}=-\delta \frac{\partial k}{\partial \bar{\theta}^{1}}>0
\end{aligned}
$$

As noted in the text, this the derivative of the price with respect to $k$ is negative only for a low or intermediate elasticity of intertemporal substitution. The result holds at least for log utility and CRRA utility with $\gamma>1$ (see Appendix C).

Part (iii): The derivative of the final ownership stake of owner 1 (equation (10)) with respect to the relative wealth $\beta$ reads:

$$
\frac{\partial \theta^{1}(k)}{\partial \beta}=\frac{\omega-k+\left(\beta-\bar{\theta}^{1}\right) \frac{\partial k}{\partial \beta}}{(1+\delta)(\omega-k)^{2}} \omega
$$


Clearly, the expression is positive for $\beta \geq \bar{\theta}^{1}$. In order to show that expression (37) is positive also when $\beta<\bar{\theta}^{1}$, we show first that it is positive for $\beta=0$. Afterwards we show that it is monotonous for $\beta$ between 0 and $\bar{\theta}^{1}$.

For $\beta=0$, we show that $\operatorname{sign}\left(\frac{\partial \theta^{1}(k)}{\partial \beta}\right)=\operatorname{sign}\left(\omega-k-\bar{\theta}^{1} \frac{\partial k}{\partial \beta}\right)$ is positive. We have

$$
\begin{aligned}
k & =\left[\frac{1+2 \delta}{2(1+\delta)}-\frac{\sqrt{(1+2 \delta)^{2}\left(\delta^{-1}+\alpha\right)-4 \alpha \delta(1+\delta)}}{2(1+\delta) \sqrt{\delta^{-1}+\alpha}}\right] \omega \\
& =\frac{(1+2 \delta) \sqrt{\delta^{-1}+\alpha}-\sqrt{\delta^{-1}+\alpha+4(1+\delta)}}{2(1+\delta) \sqrt{\delta^{-1}+\alpha}} \omega \\
\omega-k & =\frac{\sqrt{\delta^{-1}+\alpha}+\sqrt{\delta^{-1}+\alpha+4(1+\delta)}}{2(1+\delta) \sqrt{\delta^{-1}+\alpha}} \omega
\end{aligned}
$$

On the other hand, using (35) we get

$$
\begin{aligned}
-\bar{\theta}^{1} \frac{\partial k}{\partial \beta}= & \frac{1}{2}\left[\frac{1-\alpha}{(1+\delta)\left(\delta^{-1}+\alpha\right)}-\frac{2(1+\delta) \sqrt{\delta^{-1}+\alpha}}{\sqrt{\delta^{-1}+\alpha+4(1+\delta)}} \ldots\right. \\
& \left.\ldots\left(\frac{1+2 \delta}{2(1+\delta)} \frac{1-\alpha}{(1+\delta)\left(\delta^{-1}+\alpha\right)}+\frac{\alpha}{(1+\delta)\left(\delta^{-1}+\alpha\right)}\right)\right] \omega \\
= & \frac{\omega}{2(1+\delta) \sqrt{\left(\delta^{-1}+\alpha\right)}}\left(\frac{1-\alpha}{\sqrt{\left(\delta^{-1}+\alpha\right)}}-\frac{1+2 \delta+\alpha}{\sqrt{\left(\delta^{-1}+\alpha\right)+4(1+\delta)}}\right)
\end{aligned}
$$

Summing up expressions (38) and (40), we get

$$
\begin{gathered}
\omega-k-\left.\bar{\theta}^{1} \frac{\partial k}{\partial \beta}\right|_{\beta=0}=\frac{\omega}{2(1+\delta) \sqrt{\left(\delta^{-1}+\alpha\right)}}\left[\sqrt{\delta^{-1}+\alpha}+\sqrt{\delta^{-1}+\alpha+4(1+\delta)} \ldots\right. \\
\left.\ldots+\frac{1-\alpha}{\sqrt{\left(\delta^{-1}+\alpha\right)}}-\frac{1+2 \delta+\alpha}{\sqrt{\left(\delta^{-1}+\alpha\right)+4(1+\delta)}}\right] \\
=\frac{\omega}{2(1+\delta) \sqrt{\left(\delta^{-1}+\alpha\right)} \sqrt{\left(\delta^{-1}+\alpha\right)+4(1+\delta)}}\left[\sqrt{\left(\delta^{-1}+\alpha\right)} \sqrt{\left(\delta^{-1}+\alpha\right)+4(1+\delta)} \ldots\right. \\
\ldots+\frac{\sqrt{\left((1-\alpha) \delta^{-1}+\alpha\right)+4(1+\delta)}}{\sqrt{\left(\delta^{-1}+\alpha\right)}}+\underbrace{\delta^{-1}+\alpha+4(1+\delta)-(1+2 \delta+\alpha)}_{=\delta^{-1}+3+2 \delta}]>0
\end{gathered}
$$

For the second part of the argument, we write first the derivative of the function $\frac{\partial \theta^{1}(k)}{\partial \beta}$ with respect to $\beta$, i.e. the second derivative:

$$
\frac{\partial^{2} \theta^{1}(k)}{\partial \beta^{2}}=\frac{2(1+\delta)(\omega-k) \frac{\partial k}{\partial \beta}\left[\omega-k+\left(\beta-\bar{\theta}^{1}\right) \frac{\partial k}{\partial \beta}\right]}{(1+\delta)^{2}(\omega-k)^{4}} \omega
$$


Note that it has the same sign as the first derivative itself. At $\beta=0$ the function $\frac{\partial \theta^{1}(k)}{\partial \beta}$ is positive and increasing. If it would change direction, then at the turning point, say $\tilde{\beta}$, the second derivative would have to become zero. But then it must be also that $\frac{\partial \theta^{1}(k)}{\partial \beta}(\tilde{\beta})=0$. But this is a contradiction since $\frac{\partial \theta^{1}(k)}{\partial \beta}(\tilde{\beta})>\frac{\partial \theta^{1}(k)}{\partial \beta}(0)>0$. Therefore, $\frac{\partial \theta^{1}(k)}{\partial \beta}$ is positive and increasing for all $\beta \in[0,1]$.

As for the effect of the initial ownership stake $\bar{\theta}^{1}$ on the final stake, we calculate the derivative

$$
\frac{\partial \theta^{1}(k)}{\partial \bar{\theta}^{1}}=\frac{\left(\beta-\bar{\theta}^{1}\right) \frac{\partial k}{\partial \theta^{1}}-(\omega-k)}{(1+\delta)(\omega-k)^{2}} \omega
$$

Clearly, the expression is negative for $\bar{\theta}^{1} \leq \beta$. In order to show that it is also negative the case of $\bar{\theta}^{1}>\beta$, we look at the second derivative of $\theta^{1}(k)$ with respect to the initial stake $\bar{\theta}^{1}$.

$$
\frac{\partial^{2} \theta^{1}(k)}{\partial\left(\bar{\theta}^{1}\right)^{2}}=\frac{\left(\beta-\bar{\theta}^{1}\right) \frac{\partial^{2} k}{\partial\left(\bar{\theta}^{1}\right)^{2}}(\omega-k)+2\left[\left(\beta-\bar{\theta}^{1}\right) \frac{\partial k}{\partial \bar{\theta}^{1}}-(\omega-k)\right]}{(1+\delta)(\omega-k)^{3}} \omega
$$

Next, we show that $\frac{\partial^{2} k}{\partial\left(\bar{\theta}^{1}\right)^{2}}$ is positive. From (36) we calculate

$$
\begin{aligned}
\frac{\partial^{2} k}{\partial\left(\bar{\theta}^{1}\right)^{2}}= & -\frac{1}{2}\left[\frac{\partial^{2} P}{\partial\left(\bar{\theta}^{1}\right)^{2}}-\frac{1}{2}\left(\frac{P^{2}}{4}-Q\right)^{-\frac{3}{2}}\left(\frac{1}{2} P \frac{\partial P}{\partial \bar{\theta}^{1}}-\frac{\partial Q}{\partial \bar{\theta}^{1}}\right)^{2}+\left(\frac{P^{2}}{4}-Q\right)^{-\frac{1}{2}} \ldots\right. \\
& \left.\ldots\left(\frac{1}{2}\left(\frac{\partial P}{\partial \bar{\theta}^{1}}\right)^{2}+\frac{1}{2} P \frac{\partial^{2} P}{\partial\left(\bar{\theta}^{1}\right)^{2}}-\frac{\partial^{2} Q}{\partial\left(\bar{\theta}^{1}\right)^{2}}\right)\right] \omega
\end{aligned}
$$

where $\frac{\partial P}{\partial \theta^{1}}$ and $\frac{\partial Q}{\partial \theta^{1}}$ are given in (33) and (34), and

$$
\begin{aligned}
\frac{\partial^{2} P}{\partial\left(\bar{\theta}^{1}\right)^{2}} & =\frac{2(1-\alpha) \beta}{(1+\delta)\left(\delta^{-1}+\alpha\right)\left(\bar{\theta}^{1}\right)^{3}}>0 \\
\frac{\partial^{2} Q}{\partial\left(\bar{\theta}^{1}\right)^{2}} & =\frac{2 \alpha \beta}{(1+\delta)\left(\delta^{-1}+\alpha\right)\left(\bar{\theta}^{1}\right)^{3}}>0
\end{aligned}
$$

Positive terms are outweighed by negative terms:

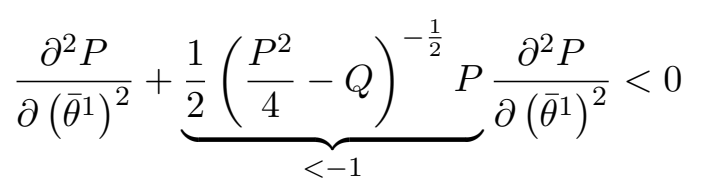

and

$$
\begin{gathered}
-\frac{1}{2}\left(\frac{P^{2}}{4}-Q\right)^{-\frac{3}{2}}\left(\frac{1}{2} P \frac{\partial P}{\partial \bar{\theta}^{1}}-\frac{\partial Q}{\partial \bar{\theta}^{1}}\right)^{2}+\frac{1}{2}\left(\frac{P^{2}}{4}-Q\right)^{-\frac{1}{2}}\left(\frac{\partial P}{\partial \bar{\theta}^{1}}\right)^{2}<0 \\
-\underbrace{\left(\frac{P^{2}}{4}-Q\right)^{-1}\left[\frac{1}{4} P^{2}\right.}_{>1}\left(\frac{\partial P}{\partial \bar{\theta}^{1}}\right)^{2}-\underbrace{P \frac{\partial P}{\partial \bar{\theta}^{1}} \frac{\partial Q}{\partial \bar{\theta}^{1}}}_{<0}+\left(\frac{\partial Q}{\partial \bar{\theta}^{1}}\right)^{2}]+\left(\frac{\partial P}{\partial \bar{\theta}^{1}}\right)^{2}<0
\end{gathered}
$$


where we have multiplied the first line by $2 \sqrt{\frac{P^{2}}{4}-Q}$ to obtain the second line, without affecting the sign of the expression. Therefore, we have that $\frac{\partial^{2} k}{\partial\left(\bar{\theta}^{1}\right)^{2}}>0$. This means for the numerator of $\frac{\partial^{2} \theta^{1}(k)}{\partial\left(\bar{\theta}^{1}\right)^{2}}$ given in equation (42) in the case where $\bar{\theta}^{1}>\beta$ and the first derivative is negative, i.e. $\left(\beta-\bar{\theta}^{1}\right) \frac{\partial k}{\partial \bar{\theta}^{1}}-(\omega-k)<0$ :

$$
\underbrace{\left(\beta-\bar{\theta}^{1}\right)}_{<0} \underbrace{\frac{\partial^{2} k}{\partial\left(\bar{\theta}^{1}\right)^{2}}}_{>0} \underbrace{(\omega-k)}_{>0}+2 \underbrace{\left[\left(\beta-\bar{\theta}^{1}\right) \frac{\partial k}{\partial \bar{\theta}^{1}}-(\omega-k)\right]}_{<0}<0
$$

That is, whenever the first derivative is negative and $\bar{\theta}^{1}>\beta$, the second derivative is negative, too. Note that the first and second derivative are negative at $\bar{\theta}^{1}=\beta$. In other words, the function $\frac{\partial \theta^{1}(k)}{\partial \bar{\theta}^{1}}$ is decreasing in $\bar{\theta}^{1}$. Consequently, it will be negative and decreasing for higher initial stakes $\bar{\theta}^{1}$, too.

Part (iv): From expression (15) for the level of investment when the non-negativity constraint binds we derive the derivatives

$$
\begin{aligned}
\frac{\partial k}{\partial \beta} & =-\frac{1}{\left(1-\bar{\theta}^{1}\right)(1+\delta)}<0 \\
\frac{\partial k}{\partial \bar{\theta}^{1}} & =\frac{1-\beta}{\left(1-\bar{\theta}^{1}\right)^{2}(1+\delta)} \geq 0
\end{aligned}
$$

These are the opposite signs of the ones found for the interior solution in part (i). From part (ii) it is clear then that also the price reacts to changes in $\beta$ or $\bar{\theta}^{1}$ in the opposite way, i.e. $\frac{\partial p(k)}{\partial \beta}>0$ and $\frac{\partial p(k)}{\partial \bar{\theta}^{1}} \leq 0$. As we argued in Appendix A.2, the constraint that has to be taken into consideration is $c_{1}^{2} \geq 0$, and, when binding, it implies that $\theta^{2}=0$ and $\theta^{1}=1$.

Part (v): On the one hand, no constraint can be binding if $\beta=\bar{\theta}^{1}$. As shown in Example 1 , under this condition both owners are unanimous, and would therefore not choose a level of investment that leads to zero or negative consumption. On the other hand, the constraint is binding whenever $k^{\text {int }} \geq k^{\text {constr }}$ (see equations (12)-(16)). Holding $\bar{\theta}^{1}$ fixed, if we increase $\beta$, we have the following effects: According to part (i), $k^{\text {int }}$ increases, and according to part (iv), $k^{\text {constr }}$ decreases. Thus, the inequality becomes more likely to hold. In contrast, it is less likely to hold when $\beta$ decreases. Since the likelihood is zero at $\beta=\bar{\theta}^{1}$, it can only hold if $\beta>\bar{\theta}^{1}$. The argument for $\bar{\theta}^{1}$ runs similarly.

Part (vi): At interior solutions, the non-negativity constraint for the controlling owner never binds since she will not optimally choose zero or negative consumption. If the constraint for owner 2 binds at $t=1$, i.e. $c_{1}^{2}=0$, then we can use equation (15), $\theta^{1}=1$, and the budget constraint (2) 
to write

$$
\begin{aligned}
c_{0}^{1} & =\beta \omega+\left(\bar{\theta}^{1}-\theta^{1}\right) p-\bar{\theta}^{1} k \\
& =\beta \omega+\frac{\left(\bar{\theta}^{1}-1\right) \delta\left(\beta-\bar{\theta}^{1}\right) \omega}{\left(1-\bar{\theta}^{1}\right)(1+\delta)}-\frac{\bar{\theta}^{1}\left(1-\beta+\delta\left(1-\bar{\theta}^{1}\right)\right) \omega}{\left(1-\bar{\theta}^{1}\right)(1+\delta)} \\
& =\frac{\left(\beta-\bar{\theta}^{1}\right) \omega}{\left(1-\bar{\theta}^{1}\right)(1+\delta)}
\end{aligned}
$$

As shown in part (v), the constraint for owner 2 can only bind if $\beta>\overline{\theta_{1}}$. But in this case, the foregoing expression is positive, i.e. the constraint for owner 1 at $t=0$ does not bind. Neither the constraint at $t=1$ binds: consumption is $c_{1}^{1}=\theta^{1} A k^{\alpha}>0$ since $\theta^{1}=1$ at corner solutions.

\section{A.4 Different preferences on intertemporal substitution}

The optimal demand for shares of owner 1, with log utility, is (see also Appendix A.1)

$$
\theta^{1}(k, p)=\frac{\delta\left(\beta \omega+\bar{\theta}^{1}(p-k)\right)}{(1+\delta) p}
$$

and for owner 2, with CRRA utility (see also Appendix C),

$$
\theta^{2}(k, p)=\frac{(1-\beta) \omega+\bar{\theta}^{2}(p-k)}{\delta^{-\frac{1}{\gamma}}\left(A k^{\alpha}\right)^{-\frac{1-\gamma}{\gamma}} p^{\frac{1}{\gamma}}+p}
$$

Market clearing $\left(\theta^{1}+\theta^{2}=1\right)$ yields an implicit function for the firm value $p(k)$ :

$$
\begin{aligned}
0 & =-\bar{\theta}^{1} p-\left(1+\delta^{-\frac{1-\gamma}{\gamma}}\left(1-\bar{\theta}^{1}\right)\right)\left(A k^{\alpha}\right)^{-\frac{1-\gamma}{\gamma}} p^{\frac{1}{\gamma}} \\
& +\delta^{-\frac{1-\gamma}{\gamma}}\left(A k^{\alpha}\right)^{-\frac{1-\gamma}{\gamma}}\left(\beta \omega-\bar{\theta}^{1} k\right) p^{\frac{1-\gamma}{\gamma}}+(1+\delta-\beta) \omega-\left(1+\delta-\bar{\theta}^{1}\right) k
\end{aligned}
$$

This expression is used to find $p(k)$ numerically, which is then used to calculate the ownership shares (43) and to solve for the optimal level of investment, problem (17).

For the case with participation constraint (section 3.1.2), the reservation utilities for both owners are given by

$$
\begin{aligned}
U_{\text {Res }}^{1} & =\ln \left(\frac{\beta}{1+\delta} \omega\right)+\delta \ln \left(\frac{\delta \beta}{1+\delta} \omega\right) \\
U_{\text {Res }}^{2} & =\frac{1}{1-\gamma}\left[\left(\frac{\delta^{-\frac{1}{\gamma}}(1-\beta)}{1+\delta^{-\frac{1}{\gamma}}} \omega\right)^{1-\gamma}+\delta\left(\frac{(1-\beta)}{1+\delta^{-\frac{1}{\gamma}}} \omega\right)^{1-\gamma}\right]
\end{aligned}
$$

\section{A.5 Proof of Proposition 3}

(i) As for the controlling owner, the derivative of (18) with respect to $\lambda$ is

$$
\frac{\partial F^{\prime}\left(k^{(1)}\right)}{\partial \lambda}=-\frac{(1+r) \bar{\theta}^{1}\left(1-\bar{\theta}^{1}\right)}{\left(\bar{\theta}^{1}(1-\lambda)+\lambda\right)^{2}}<0
$$


Since $F^{\prime}$ is a decreasing function, $k^{(1)}$ is increasing in $\lambda$. As for the non-controlling owner, the derivative of (19) with respect to $\lambda$ is positive, therefore $k^{(2)}$ is decreasing in $\lambda$.

(ii) The derivative of (18) with respect to $\bar{\theta}^{1}$ is

$$
\frac{\partial F^{\prime}\left(k^{(1)}\right)}{\partial \bar{\theta}^{1}}=\frac{(1+r) \lambda}{\left(\bar{\theta}^{1}(1-\lambda)+\lambda\right)^{2}}>0
$$

Therefore, $k^{(1)}$ is decreasing in $\bar{\theta}^{1}$. It is immediate from (19) that $k^{(2)}$ does not depend on the initial ownership stake.

\section{A.6 Proof of Proposition 4 and exact conditions for final shareholdings with private benefits}

We use (20) to write the change in the asset position of owner 1

$$
\begin{aligned}
\theta^{1}(k)-\bar{\theta}^{1} & =\frac{\left(\beta-\bar{\theta}^{1}\right) \omega-\lambda\left(1-\bar{\theta}^{1}\right)(\omega-k)}{(1+\delta)(1-\lambda)(\omega-k)} \\
& =\frac{\left[\beta-\left(\bar{\theta}^{1}(1-\lambda)+\lambda\right)\right]+\lambda\left(1-\bar{\theta}^{1}\right) k}{(1+\delta)(1-\lambda)(\omega-k)}
\end{aligned}
$$

This gives immediately the two conditions given in the proposition. For the special case of proportional endowments $\bar{\theta}^{1}=\beta$, this simplifies to

$$
\theta^{1}(k)-\bar{\theta}^{1}=-\frac{\lambda\left(1-\bar{\theta}^{1}\right)}{(1+\delta)(1-\lambda)}<0
$$

and the change in the shareholdings of both agents becomes independent of investment.

Next we derive exact necessary conditions for the direction of change of the shareholdings of owner 1 (not given in Proposition 4). From (44) we see that $\theta^{1}(k)-\bar{\theta}^{1} \gtreqless 0$ if and only if

$$
k \gtreqless \frac{\bar{\theta}^{1}(1-\lambda)+\lambda-\beta}{\left(1-\bar{\theta}^{1}\right) \lambda} \omega
$$

Using (21) this is satisfied if and only if

$$
-\frac{P_{\lambda}}{2}-\sqrt{\frac{P_{\lambda}^{2}}{4}-Q_{\lambda}}-\frac{\bar{\theta}^{1}(1-\lambda)+\lambda-\beta}{\left(1-\bar{\theta}^{1}\right) \lambda} \gtreqless 0
$$

with $P_{\lambda}$ and $Q_{\lambda}$ defined in equations (22) and (23). The value of $\beta$ for which the expression becomes equal to zero lies between $\bar{\theta}^{1}$ and $\bar{\theta}^{1}(1-\lambda)+\lambda$ as stated in Proposition 4 .

\section{A.7 Proof of Proposition 5}

We need to find out how $k$, given in equation (21) changes with the proportion of dividends that are appropriated by owner 1 as private benefits $\lambda$. In a preliminary step we calculate the 
derivatives of $P_{\lambda}$ and $Q_{\lambda}$ as given in equations (22) and (23) with respect to $\lambda$

$$
\begin{aligned}
\frac{\partial P_{\lambda}}{\partial \lambda} & =\frac{\delta\left(1-\bar{\theta}^{1}\right)(1-\alpha)\left(\bar{\theta}^{1}-\beta\right)}{\left(\delta^{-1}+\alpha\right)\left[(1+\delta) \bar{\theta}^{1}+\delta \lambda\left(1-\bar{\theta}^{1}\right)\right]^{2}} \\
\frac{\partial Q_{\lambda}}{\partial \lambda} & =\frac{\alpha \delta\left(1-\bar{\theta}^{1}\right)\left(\bar{\theta}^{1}-\beta\right)}{\left(\delta^{-1}+\alpha\right)\left[(1+\delta) \bar{\theta}^{1}+\delta \lambda\left(1-\bar{\theta}^{1}\right)\right]^{2}}
\end{aligned}
$$

Next, we prove that $P_{\lambda}$ is a negative number. Note that the denominator in equation (22) is positive, but the numerator and therefore $P_{\lambda}$ is negative because

$$
\left(\delta^{-1}+\alpha\right)(1+2 \delta) \bar{\theta}^{1}+(2 \alpha \delta+1) \lambda\left(1-\bar{\theta}^{1}\right)>2 \bar{\theta}^{1}>(1-\alpha) \beta
$$

(Recall that by assumption $\bar{\theta}^{1} \geq 0.5, \alpha \in(0,1)$ and $\beta \in[0,1]$.) Now we calculate from equation (21) the derivative of $k$ with respect to $\lambda$ :

$$
\frac{\partial k}{\partial \lambda}=\left[-\frac{1}{2} \frac{\partial P_{\lambda}}{\partial \lambda}-\frac{1}{2}\left(\frac{P_{\lambda}^{2}}{4}-Q_{\lambda}\right)^{-\frac{1}{2}}\left(\frac{1}{2} P_{\lambda} \frac{\partial P_{\lambda}}{\partial \lambda}-\frac{\partial Q_{\lambda}}{\partial \lambda}\right)\right] \omega
$$

- Suppose that $\bar{\theta}^{1}>\beta$. In this case we have $\frac{\partial P_{\lambda}}{\partial \lambda}>0$ and $\frac{\partial Q_{\lambda}}{\partial \lambda}>0$. In order to prove that in this case $\frac{\partial k}{\partial \lambda}>0$, one can see from (45) that it suffices to show that $\frac{1}{2}\left(\frac{P_{\lambda}^{2}}{4}-Q_{\lambda}\right)^{-\frac{1}{2}} P_{\lambda}<-1$. This is done in the proof in Appendix A.3, part (i) - all what we need is that $Q_{\lambda}>0$. This can be easily verified using equation (23).

- Suppose that $\bar{\theta}^{1}<\beta$. In this case we have $\frac{\partial P_{\lambda}}{\partial \lambda}<0$ and $\frac{\partial Q_{\lambda}}{\partial \lambda}<0$. With the same argument as in the previous case it can be shown that $\frac{\partial k}{\partial \lambda}<0$.

- In the remaining case $\bar{\theta}^{1}=\beta$, we have $\frac{\partial P_{\lambda}}{\partial \lambda}=0$ and $\frac{\partial Q_{\lambda}}{\partial \lambda}=0$, and it follows directly from (45) that $\frac{\partial k}{\partial \lambda}=0$.

\section{A.8 Final ownership stakes and private benefits}

Write the optimal level of investment as $k=C \omega$ where $C$ is given in equations (21)-(23). Using expression (44) we have

$$
\theta^{1}(k)-\bar{\theta}^{1}=\frac{\beta-\bar{\theta}^{1}}{(1+\delta)(1-\lambda)(1-C)}-\frac{\lambda\left(1-\bar{\theta}^{1}\right)}{(1+\delta)(1-\lambda)}
$$

Using this expression we derive the effect of a higher fraction of private benefits $\lambda$ on the final ownership stake of the controlling owner.

$$
\frac{\partial \theta^{1}(k)}{\partial \lambda}=\frac{\left(\beta-\bar{\theta}^{1}\right)\left[1-C+(1-\lambda) \frac{\partial C}{\partial \lambda}\right]-\left(1-\bar{\theta}^{1}\right) \lambda(1-C)^{2}}{(1+\delta)(1-\lambda)^{2}(1-C)^{2}}
$$

For the case $\bar{\theta}^{1} \geq \beta$ this expression becomes clearly negative (recall from Proposition 5 that $\partial C / \partial \lambda \geq 0$ in this case). We do however not derive a condition when the effect becomes zero or positive. This would just be a complicated function of the model parameters without great insight. We conjecture that for large $\beta$ the expression might become positive. 


\section{A.9 Equilibria in the two-period model with private benefits and proof of Proposition 6}

We derive the solutions for cases A, B, C and D backwards in time. Attention is restricted to interior solutions.

Case A. The first-order conditions for the optimal stakes at date $t=1 \mathrm{read}$

$$
\begin{aligned}
\frac{\partial U^{1}}{\partial \theta_{1}^{1}} & =\frac{-p_{1}}{\left((1-\lambda) \theta_{0}^{1}+\lambda\right) A k_{0}^{\alpha}+\left(\theta_{0}^{1}-\theta_{1}^{1}\right) p_{1}-\theta_{0}^{1} k_{1}}+\frac{\delta(1-\lambda)}{(1-\lambda) \theta_{0}^{1}+\lambda}=0 \\
\frac{\partial U^{2}}{\partial \theta_{1}^{2}} & =\frac{-p_{1}}{(1-\lambda) \theta_{0}^{2} A k_{0}^{\alpha}+\left(\theta_{0}^{2}-\theta_{1}^{2}\right) p_{1}-\theta_{0}^{2} k_{1}}+\frac{\delta}{\theta_{0}^{2}}=0
\end{aligned}
$$

Imposing the market clearing condition $\left(\theta_{1}^{1}+\theta_{1}^{2}=1\right)$ yields the optimal ownership stakes and the value of the firm at time $t=1$

$$
\begin{aligned}
p_{1} & =\delta(1-\lambda)\left(A k_{0}^{\alpha}-k_{1}\right) \\
\theta_{1}^{1}\left(k_{0}, \theta_{0}^{1}, k_{1}\right) & =\theta_{0}^{1}+\frac{\left(1-\theta_{0}^{1}\right) \lambda k_{1}}{(1+\delta)(1-\lambda)\left(A k_{0}^{\alpha}-k_{1}\right)} \\
\theta_{1}^{2}\left(k_{0}, \theta_{0}^{2}, k_{1}\right) & =\theta_{0}^{2}-\frac{\theta_{0}^{2} \lambda k_{1}}{(1+\delta)(1-\lambda)\left(A k_{0}^{\alpha}-k_{1}\right)}
\end{aligned}
$$

We see that the ownership stake of the owner with private benefits is increasing in the last trading period. This proves Proposition 6 for case A. Next, we derive the investment decision at $t=1$.

In the present case, owner 1 decides on the level of investment $k_{1}$ no matter what her ownership stake $\theta_{0}^{1}$ is. The first-order condition for optimal investment reads

$$
\frac{\partial U^{1}}{\partial k_{1}}=-\frac{\theta_{0}^{1}+\delta(1-\lambda)\left(\theta_{0}^{1}-\theta_{1}^{1}\right)}{\left((1-\lambda) \theta_{0}^{1}+\lambda\right) A k_{0}^{\alpha}+\left(\theta_{0}^{1}-\theta_{1}^{1}\right) p_{1}-\theta_{0}^{1} k_{1}}+\frac{\delta \alpha}{k_{1}}=0
$$

Using (48) to (50) this yields the interior solution for $k_{1}$ in terms of the previously determined variables $k_{0}$ and $\theta_{0}^{1}$, given by the following expression

$$
k_{1}=\left(-\frac{P_{1}}{2}-\sqrt{\frac{P_{1}^{2}}{4}-Q_{1}}\right) A k_{0}^{\alpha}
$$

where

$$
\begin{aligned}
P_{1} & =-\frac{\delta \alpha(1+2 \delta)\left[(1-\lambda) \theta_{0}^{1}+\lambda\right]+[1+\delta(1+\alpha)] \theta_{0}^{1}}{(1+\delta \alpha)\left[(1+\delta) \theta_{0}^{1}+\delta \lambda\left(1-\theta_{0}^{1}\right)\right]} \\
Q_{1} & =\frac{\delta \alpha(1+\delta)\left[(1-\lambda) \theta_{0}^{1}+\lambda\right]}{(1+\delta \alpha)\left[(1+\delta) \theta_{0}^{1}+\delta \lambda\left(1-\theta_{0}^{1}\right)\right]}
\end{aligned}
$$

Note that we get a similar solution to the one-period model (just replace the endowment $\omega$ by first-period production $A k_{0}^{\alpha}$ and owner 1's wealth share $\beta$ by $(1-\lambda) \theta_{0}^{1}+\lambda$ in equations (22) and (23).) 
Going back in time, we can derive the optimality conditions for the demand for shares of each owner at $t=0$. The first-order condition for owner 1 reads

$$
\frac{\partial U^{1}}{\partial \theta_{0}^{1}}=\frac{-p_{0}}{\beta \omega+\left(\bar{\theta}_{0}^{1}-\theta_{0}^{1}\right) p_{0}-\bar{\theta}_{0}^{1} k_{0}}+\frac{\delta\left[(1-\lambda) A k_{0}^{\alpha}+p_{1}-k_{1}\right]}{\left((1-\lambda) \theta_{0}^{1}+\lambda\right) A k_{0}^{\alpha}+\left(\theta_{0}^{1}-\theta_{1}^{1}\right) p_{1}-\theta_{0}^{1} k_{1}}=0
$$

Note that we used the FOC for $k_{1}$ (equation (51)) and the FOC for $\theta_{1}^{1}$ (equation 46) to cancel terms involving the derivatives of $k_{1}$ and $\theta_{1}^{1}$ with respect to $\theta_{0}^{1}$. Using expressions (48) to (50) we derive the optimal demand for shares of owner 1 at $t=0$ as a function of $p_{0}, k_{0}$ and $k_{1}$ :

$$
\theta_{0}^{1}=\frac{\delta(1+\delta)}{1+\delta+\delta^{2}} \frac{\beta \omega+\bar{\theta}_{0}^{1}\left(p_{0}-k_{0}\right)}{p_{0}}-\frac{\lambda\left[(1+\delta) A k_{0}^{\alpha}-\delta k_{1}\right]}{\left(1+\delta+\delta^{2}\right)\left[(1+\delta)(1-\lambda)\left(A k_{0}^{\alpha}-k_{1}\right)-\lambda k_{1}\right]}
$$

The first-order condition for owner 2 reads

$$
\begin{aligned}
\frac{\partial U^{2}}{\partial \theta_{0}^{2}} & =\frac{-p_{0}}{(1-\beta) \omega+\left(\bar{\theta}_{0}^{2}-\theta_{0}^{2}\right) p_{0}-\bar{\theta}_{0}^{2} k_{0}} \\
& +\frac{\delta\left[(1-\lambda) A k_{0}^{\alpha}+p_{1}-k_{1}+\left(\left(\theta_{0}^{2}-\theta_{1}^{2}\right) \frac{\partial p_{1}}{\partial k_{1}}-\theta_{0}^{2}\right)\left(-\frac{\partial k_{1}}{\partial \theta_{0}^{1}}\right)\right]}{(1-\lambda) \theta_{0}^{2} A k_{0}^{\alpha}+\left(\theta_{0}^{2}-\theta_{1}^{2}\right) p_{1}-\theta_{0}^{2} k_{1}}+\frac{\delta^{2} \alpha\left(-\frac{\partial k_{1}}{\partial \theta_{0}^{1}}\right)}{k_{1}}=0
\end{aligned}
$$

Again, we used the FOC for $\theta_{1}^{2}$ (equation 47) to cancel terms involving the derivatives of $\theta_{1}^{2}$ with respect to $\theta_{0}^{2}$. For owner 2, however, we cannot use the FOC for $k_{1}$ to cancel terms involving the derivative of $k_{1}$ with respect to $\theta_{0}^{2}$ since $k_{1}$ is not chosen optimally from the viewpoint of owner 2. Owner 2 has to take the effect of his demand for shares today on investment tomorrow into account explicitly. Therefore, the derivative shows up in the previous equation. (Note that $\frac{\partial k_{1}}{\partial \theta_{0}^{2}}=-\frac{\partial k_{1}}{\partial \theta_{0}^{1}}$.)

Expression (54) can be simplified to

$$
\begin{aligned}
\frac{\partial U^{2}}{\partial \theta_{0}^{2}} & =\frac{-p_{0}}{(1-\beta) \omega+\left(\bar{\theta}_{0}^{2}-\theta_{0}^{2}\right) p_{0}-\bar{\theta}_{0}^{2} k_{0}}+\frac{\delta(1+\delta)}{\theta_{0}^{2}} \\
& +\delta\left(\frac{\delta \alpha}{k_{1}}-\frac{(1+\delta)\left(A k_{0}^{\alpha}-k_{1}\right)+\delta \lambda k_{1}}{\left(A k_{0}^{\alpha}-k_{1}\right)\left[(1+\delta)(1-\lambda)\left(A k_{0}^{\alpha}-k_{1}\right)-\lambda k_{1}\right]}\right)\left(-\frac{\partial k_{1}}{\partial \theta_{0}^{1}}\right)=0
\end{aligned}
$$

The derivative expression in (55) is calculated from (52) and reads

$$
\frac{\partial k_{1}}{\partial \theta_{0}^{1}}=\left[-\frac{1}{2} \frac{\partial P_{1}}{\partial \theta_{0}^{1}}-\frac{1}{2}\left(\frac{P_{1}^{2}}{4}-Q_{1}\right)^{-\frac{1}{2}}\left(\frac{1}{2} P_{1} \frac{\partial P_{1}}{\partial \theta_{0}^{1}}-\frac{\partial Q_{1}}{\partial \theta_{0}^{1}}\right)\right] A k_{0}^{\alpha}
$$

where

$$
\begin{aligned}
\frac{\partial P_{1}}{\partial \theta_{0}^{1}} & =-\frac{\delta(1+\delta)(1-\alpha) \lambda}{(1+\delta \alpha)\left[(1+\delta) \theta_{0}^{1}+\delta \lambda\left(1-\theta_{0}^{1}\right)\right]^{2}} \\
\frac{\partial Q_{1}}{\partial \theta_{0}^{1}} & =-\frac{\delta(1+\delta) \alpha \lambda}{(1+\delta \alpha)\left[(1+\delta) \theta_{0}^{1}+\delta \lambda\left(1-\theta_{0}^{1}\right)\right]^{2}}
\end{aligned}
$$


Now we have a system of three nonlinear equations - for the optimal investment(52), and the two first-order conditions for optimal ownership stakes (53) and (55). Using also the market clearing condition, i.e. substituting $\theta_{0}^{2}$ by $1-\theta_{0}^{1}$ in (55), and the expression for the derivative (56) we can solve this system numerically to obtain values of $k_{1}, \theta_{0}^{1}$ and $p_{0}$ for any given value of $k_{0}$. It remains only to maximize the indirect utility function of the initial majority owner 1 with respect to $k_{0}$ to obtain the full solution.

Case B. Since owner 1 always receives the private benefits, the budget constraints are unchanged with respect to case A. Hence, equations (48) to (50) for the share price and ownership stakes at $t=1$ apply, which proves Proposition 6 also for case B.

Suppose that owner 1 holds a majority after the first round of trading, i.e. $\theta_{0}^{1} \geq 0.5$. Then the solution of case $\mathrm{A}$ applies also here (owner 1 decides on investment $k_{1}$ and extracts private benefits at $t=2)$.

Now suppose that $\theta_{0}^{1}<0.5$, i.e. owner 2 decides on $k_{1}$. The optimal amount of investment in this case is given by:

$$
k_{1}=\left(-\frac{P_{B 2}}{2}-\sqrt{\frac{P_{B 2}^{2}}{4}-Q_{B 2}}\right) A k_{0}^{\alpha}
$$

where

$$
\begin{aligned}
P_{B 2} & =-\frac{(1+\delta)(1+2 \delta \alpha)-(1+2 \delta) \delta \alpha \lambda}{(1+\delta \alpha)[1+\delta(1-\lambda)]} \\
Q_{B 2} & =\frac{\alpha \delta(1+\delta)(1-\lambda)}{(1+\delta \alpha)[1+\delta(1-\lambda)]}
\end{aligned}
$$

The two equations characterizing the optimal demand for shares at $t=1 \mathrm{read}$

$$
\begin{aligned}
\theta_{0}^{1} & =\frac{\delta(1+\delta)}{1+\delta+\delta^{2}} \frac{\beta \omega+\bar{\theta}_{0}^{1}\left(p_{0}-k_{0}\right)}{p_{0}}-\frac{(1+\delta) \lambda\left(A k_{0}^{\alpha}-k_{1}\right)+\lambda k_{1}}{\left(1+\delta+\delta^{2}\right)\left[(1+\delta)(1-\lambda)\left(A k_{0}^{\alpha}-k_{1}\right)-\lambda k_{1}\right]} \\
\theta_{0}^{2} & =\frac{\delta(1+\delta)}{1+\delta+\delta^{2}} \frac{(1-\beta) \omega+\bar{\theta}_{0}^{2}\left(p_{0}-k_{0}\right)}{p_{0}}
\end{aligned}
$$

The market-clearing price is

$$
p_{0}=\frac{\delta\left(\omega-k_{0}\right)\left[(1+\delta)(1-\lambda)\left(A k_{0}^{\alpha}-k_{1}\right)-\lambda k_{1}\right]}{A k_{0}^{\alpha}-k_{1}}
$$

Substituting the solution for $k_{1}$ here, and then substituting the price back to one of the demand equations yields the ownership stakes as a function of $k_{0}$ only. So we obtain again a system of three equations leading to a solution for $k_{1}, \theta_{0}^{1}$ and $p_{0}$ as functions of $k_{0}$.

Now it remains to maximize the indirect utility function of the initial majority owner 1 with respect to $k_{0}$. If the result for the ownership stake of owner 1 is indeed, then the first solution 
(with assumption $\theta_{0}^{1} \geq 0.5$ ) is a consistent one. If $\theta_{0}^{1}<0.5$, then the optimal level of investment $k_{0}$ is calculated using the second solution (with assumption $\theta_{0}^{1}<0.5$ ). ${ }^{34}$ In this way we get the optimal values of investment, shareholdings and prices at dates 0 and 1.

Case C. Suppose that $\theta_{0}^{1} \geq 0.5$. Again, owner 1 decides on investment $k_{1}$ and extracts private benefits at $t=2$. Hence, equations (48) to (50) apply, and we follow the solution of case A.

Now suppose that $\theta_{0}^{1}<0.5$. Now private benefits go to owner 2 , as described by equations (24), (25), (26) and (27). Optimal ownership stakes and the value of the firm at time $t=1$ are given by

$$
\begin{aligned}
p_{1} & =\delta(1-\lambda)\left(A k_{0}^{\alpha}-k_{1}\right) \\
\theta_{1}^{1}\left(k_{0}, \theta_{0}^{1}, k_{1}\right) & =\theta_{0}^{1}+\frac{\lambda\left(A k_{0}^{\alpha}-\theta_{0}^{1} k_{1}\right)}{(1+\delta)(1-\lambda)\left(A k_{0}^{\alpha}-k_{1}\right)} \\
\theta_{1}^{2}\left(k_{0}, \theta_{0}^{2}, k_{1}\right) & =\theta_{0}^{2}-\frac{\lambda\left(A k_{0}^{\alpha}-\theta_{0}^{1} k_{1}\right)}{(1+\delta)(1-\lambda)\left(A k_{0}^{\alpha}-k_{1}\right)}
\end{aligned}
$$

Note that the expression for the firm value is unchanged with respect to the first solution where $\theta_{0}^{1} \geq 0.5$. Although the expressions for the ownership stakes are different from the first solution, but they prove that Proposition 6 is true also for case $\mathrm{C}$ - the owner who initially holds a majority and receives private benefits at $t=1$, increases her stake.

A different set of optimality conditions obtains for $k_{1}$ (determined by owner 2 ), $\theta_{0}^{1}$ and $\theta_{0}^{2}$.

$$
k_{1}=\left(-\frac{P_{C 2}}{2}-\sqrt{\frac{P_{C 2}^{2}}{4}-Q_{C 2}}\right) A k_{0}^{\alpha}
$$

where

$$
\begin{aligned}
P_{C 2} & =-\frac{\delta \lambda+\left(1-\theta_{0}^{1}\right)[(1+\delta)(1+2 \delta \alpha)-\lambda \delta \alpha]}{(1+\delta \alpha)\left[\delta \lambda \theta_{0}^{1}+(1+\delta)\left(1-\theta_{0}^{1}\right)\right]} \\
Q_{C 2} & =\frac{\delta \alpha(1+\delta)(1-\lambda)\left(1-\theta_{0}^{1}\right)+\delta^{2} \lambda \alpha}{(1+\delta \alpha)\left[\delta \lambda \theta_{0}^{1}+(1+\delta)\left(1-\theta_{0}^{1}\right)\right]}
\end{aligned}
$$

\footnotetext{
${ }^{34} \mathrm{We}$ do not prove the existence of an equilibrium here. There is a potential problematic case where $\theta_{0}^{1}$ turns out to be less than 0.5 when we assume that it is greater or equal, and $\theta_{0}^{1} \geq 0.5$ when we assume $\theta_{0}^{1}<0.5$. However, in all numerical solutions, the ownership stake with the second solution is smaller than with the first one, which means that always one of the two solutions is consistent with the assumption on $\theta_{0}^{1}$.
} 
We obtain two equations characterizing the optimal demand for shares at $t=1$ :

$$
\begin{aligned}
\theta_{0}^{2} & =\frac{\delta(1+\delta)}{1+\delta+\delta^{2}} \frac{(1-\beta) \omega+\bar{\theta}_{0}^{2}\left(p_{0}-k_{0}\right)}{p_{0}}-\frac{\delta \lambda\left(A k_{0}^{\alpha}-k_{1}\right)}{\left(1+\delta+\delta^{2}\right)\left[(1+\delta)(1-\lambda)\left(A k_{0}^{\alpha}-k_{1}\right)-\lambda k_{1}\right]} \\
\frac{\partial U^{1}}{\partial \theta_{0}^{1}} & =\frac{-p_{0}}{\beta \omega+\left(\bar{\theta}_{0}^{1}-\theta_{0}^{1}\right) p_{0}-\bar{\theta}_{0}^{1} k_{0}}+\frac{\delta(1+\delta)\left[(1+\delta)(1-\lambda)\left(A k_{0}^{\alpha}-k_{1}\right)-\lambda k_{1}\right]}{\theta_{0}^{1}(1+\delta)(1-\lambda)\left(A k_{0}^{\alpha}-k_{1}\right)+\lambda\left(A k_{0}^{\alpha}-\theta_{0}^{1} k_{1}\right)} \\
& +\delta\left(\frac{\delta \alpha}{k_{1}}-\frac{\left((1+\delta) \theta_{0}^{1}-\delta \lambda\right) A k_{0}^{\alpha}-\theta_{0}^{1}[1+\delta(1-\lambda)] k_{1}}{\left(A k_{0}^{\alpha}-k_{1}\right)\left[\theta_{0}^{1}(1+\delta)(1-\lambda)\left(A k_{0}^{\alpha}-k_{1}\right)+\lambda\left(A k_{0}^{\alpha}-\theta_{0}^{1} k_{1}\right)\right]}\right)\left(\frac{\partial k_{1}}{\partial \theta_{0}^{1}}\right)=0
\end{aligned}
$$

The derivative $\partial k_{1} / \partial \theta_{0}^{1}$ is of the same form as (56) with $P_{1}$ and $Q_{1}$ substituted by $P_{b 2}$ and $Q_{b 2}$ and

$$
\begin{aligned}
\frac{\partial P_{C 2}}{\partial \theta_{0}^{1}} & =-\frac{\delta^{2} \lambda[\lambda(1-\alpha)+2 \alpha(1+\delta)}{(1+\delta \alpha)\left[\delta \lambda \theta_{0}^{1}+(1+\delta)\left(1-\theta_{0}^{1}\right)\right]^{2}} \\
\frac{\partial Q_{C 2}}{\partial \theta_{0}^{1}} & =-\frac{(\delta \lambda)^{2} \alpha}{(1+\delta \alpha)\left[\delta \lambda \theta_{0}^{1}+(1+\delta)\left(1-\theta_{0}^{1}\right)\right]^{2}}
\end{aligned}
$$

Together with the market clearing condition, these variables as well as $p_{0}$ can be determined as functions of $k_{0}$. It remains to optimize with respect to $k_{0}$ and to choose the consistent one of the two solutions as described for case B.

Case D. The optimal stakes and the price at $t=1$ can be seen directly from equations (48) to (50) setting $\lambda=0$ : we get $\theta_{1}^{i}=\theta_{0}^{i}$ and $p_{1}=\delta\left(A k_{0}^{\alpha}-k_{1}\right)$. There is no reason to trade shares at $t=1$ since the ownership stake and the share that every owner gets from period 0 production are identical by assumption (the case of proportional endowments in the basic one-period model). This implies the simplified budget constraints

$$
\begin{aligned}
& c_{1}^{i}=\theta_{0}^{i}\left(A k_{0}^{\alpha}-k_{1}\right) \\
& c_{2}^{i}=\theta_{0}^{i} A k_{1}^{\alpha}
\end{aligned}
$$

Both owners are unanimous about investment in period 1 and would choose

$$
k_{1}=\frac{\alpha \delta}{1+\alpha \delta} A k_{0}^{\alpha}
$$

Stakes and the price at $t=0$ are

$$
\begin{aligned}
& p_{0}=\delta(1+\delta)\left(\omega-k_{0}\right) \\
& \theta_{0}^{1}=\frac{\left(\beta+\delta(1+\delta) \bar{\theta}_{0}^{1}\right) \omega-\left(1+\delta+\delta^{2}\right) \bar{\theta}_{0}^{1} k_{0}}{\left(1+\delta+\delta^{2}\right)\left(\omega-k_{0}\right)}
\end{aligned}
$$


The investment decision at $t=0$ is made by owner 1 , the original majority owner and leads to

$$
k_{0}=\left(-\frac{P_{0}}{2}-\sqrt{\frac{P_{0}^{2}}{4}-Q_{0}}\right) \omega
$$

where

$$
\begin{aligned}
P_{0} & =-\frac{\left(1+\alpha \delta+(\alpha \delta)^{2}\right)\left(1+2 \delta+2 \delta^{2}\right) \bar{\theta}_{0}^{1}-(1+\delta-\alpha(1+\alpha \delta)) \delta \beta}{\left(1+\alpha \delta+(\alpha \delta)^{2}\right)\left(1+\delta+\delta^{2}\right) \bar{\theta}_{0}^{1}} \\
Q_{0} & =\frac{\alpha \delta(1+\alpha \delta)\left(\beta+\delta(1+\delta) \bar{\theta}_{0}^{1}\right)}{\left(1+\alpha \delta+(\alpha \delta)^{2}\right)\left(1+\delta+\delta^{2}\right) \bar{\theta}_{0}^{1}}
\end{aligned}
$$

\section{B The complete markets version of the basic model}

In this appendix, we present a benchmark model with complete markets. The assumptions are those of the basic model outlined in section 2, except that here owners are allowed to trade a bond which pays (an exogenous) interest rate $r$ in addition to the firm shares. The amount of bonds is denominated by $b^{i}$. With this modification, owners can borrow without limit to invest in the shares of the firm. The models are therefore not comparable quantitatively in terms of the amounts invested. But the complete markets model is useful to show qualitative differences to our setup, in particular the necessary conditions for the Fisher separation theorem to hold.

The budget constraints, here presented with a general neoclassical production function $F(k)$, are modified as follows:

$$
\begin{aligned}
c_{0}^{i} & =\omega^{i}+\left(\bar{\theta}^{i}-\theta^{i}\right) p-\bar{\theta}^{i} k-b^{i} \\
c_{1}^{i} & =\theta^{i} F(k)+(1+r) b^{i} \quad i=1,2
\end{aligned}
$$

Time-additive expected utility with a standard instantaneous utility function $u(c)$ is given by

$$
U^{i}=u\left(c_{0}^{i}\right)+\delta u\left(c_{1}^{i}\right)
$$

The two pairs of first-order conditions for the optimal ownership stake and bondholdings of each owner read

$$
\begin{aligned}
& \frac{\partial U^{i}}{\partial \theta^{i}}=-p u^{\prime}\left(c_{0}^{i}\right)+\delta F(k) u^{\prime}\left(c_{1}^{i}\right)=0 \\
& \frac{\partial U^{i}}{\partial b^{i}}=-u^{\prime}\left(c_{0}^{i}\right)+\delta(1+r) u^{\prime}\left(c_{1}^{i}\right)=0
\end{aligned}
$$

From these conditions, the share price is $p=\frac{F(k)}{1+r}$. Since the firm technology exhibits decreasing returns to scale and returns of shares and bonds have to be the same, the price has to increase 
with the level of investment $k$. Given this price, both assets are equivalent (have the same return). Therefore, the optimal bond and shareholdings cannot be uniquely determined. ${ }^{35}$

One basic result is that in complete markets, the decisions on share trading and investment can be done separately. Namely, maximizing with respect to the level of investment $k$ gives the following first-order condition:

$$
\frac{\partial U^{i}}{\partial k}=\left[\left(\bar{\theta}^{i}-\theta^{i}\right) \frac{F^{\prime}(k)}{1+r}-\bar{\theta}^{i}\right] u^{\prime}\left(c_{0}^{i}\right)+\delta \theta^{i} F^{\prime}(k) u^{\prime}\left(c_{1}^{i}\right)=0
$$

which yields the rule for optimal investment

$$
F^{\prime}(k)=1+r
$$

Note that this is equivalent to the maximization of the net value of the firm or discounted profits $\max _{k} p-k=\max _{k} \frac{F(k)}{1+r}-k$. This equivalence is an instance of the Fisher separation theorem. The owners agree on a level of investment which maximizes the value of the firm and then trade bonds and shares towards their preferred consumption-saving point.

What would change if we endogenized the interest rate? That means that the two owners can only borrow and lend from each other and the interest rate is determined by the market clearing condition, $b^{1}+b^{2}=0$. This implies, for the case of log utility and a Cobb-Douglas production function, that the gross interest rate satisfies $1+r=\frac{A k^{\alpha}}{\delta(\omega-k)}$. Still, individual asset holdings are not determined. There is now a fundamental change for the unanimity result: When the interest rate is endogenous, it depends on the investment decision: if $k$ is high, then there are relatively few resources available at $t=0$ and many resources available at $t=1$, so the interest rate would be relatively low. That means there is no asset which payoffs are independent of the investment decision. That makes the Fisher separation theorem break down - shareholders will not agree on investment.

\section{The basic model with CRRA preferences}

In this appendix, we analyze the basic model with the power utility function with constant relative risk aversion coefficient $\gamma$. We assume that owners are risk-averse or risk-neutral, i.e. $\gamma \geq 0$. The expected utility function of owner $i$ reads:

$$
U^{i}=\frac{1}{1-\gamma}\left(c_{0}^{i}\right)^{1-\gamma}+\frac{\delta}{1-\gamma}\left(c_{1}^{i}\right)^{1-\gamma}
$$

where $\delta$ is the discount factor. Recall that the limit of the equivalent instantaneous utility function $\frac{1}{1-\gamma} c^{1-\gamma}-1$ when $\gamma \rightarrow 1$ is $\ln c$, i.e. the $\log$ utility function used in the main text is a special case of the power utility.

\footnotetext{
${ }^{35}$ Technically, after determining the price, we have left two optimality conditions plus one market clearing condition for shares $\left(\theta^{1}+\theta^{2}=1\right)$, but we have four unknown variables - bonds and ownership stakes of each owner. Thus, the solution to this system of equations is not unique.
} 
Solving for the exchange equilibrium provides us with optimal ownership stake of each owner as a function of the firm value and investment:

$$
\theta^{i}(k, p)=\frac{\omega^{i}+\bar{\theta}^{i}(p-k)}{\delta^{-\frac{1}{\gamma}}\left(A k^{\alpha}\right)^{-\frac{1-\gamma}{\gamma}} p^{\frac{1}{\gamma}}+p}
$$

After imposing market clearing $\left(\theta^{1}+\theta^{2}=1\right)$ we obtain the share price

$$
p(k)=(\omega-k)^{\gamma} \delta\left(A k^{\alpha}\right)^{1-\gamma}
$$

Note that $k$ may affect the price in a positive or negative manner, depending on the coefficient of relative risk aversion $\gamma$ :

$$
\frac{\partial p(k)}{\partial k}=\delta A^{1-\gamma} k^{\alpha(1-\gamma)-1}(\omega-k)^{\gamma-1}[\alpha(1-\gamma)(\omega-k)-\gamma k]
$$

For moderate and high levels of risk aversion $(\gamma \geq 1)$, or, more appropriate for a model of certainty, moderate and low levels of elasticity of intertemporal substitution, the term in brackets and therefore the whole expression become negative. For low levels of $\gamma$, near to zero (risk neutrality) however the effect of investment on firm value may become positive. ${ }^{36}$ In this case, owners are not interested in smoothing consumption between both periods, so a high investment and high returns are preferred.

Substituting in the previous equations for the optimal stakes,

$$
\begin{aligned}
\theta^{i}(k) & =\frac{\omega^{i}+\bar{\theta}^{i}(p(k)-k)}{\omega+p(k)-k} \\
& =\frac{\omega^{i}+\bar{\theta}^{i}\left[(\omega-k)^{\gamma} \delta\left(A k^{\alpha}\right)^{1-\gamma}-k\right]}{\omega+(\omega-k)^{\gamma} \delta\left(A k^{\alpha}\right)^{1-\gamma}-k}
\end{aligned}
$$

Proposition 1 in the main text also holds with CRRA preferences.

In order to solve for the production-exchange equilibrium we have to find the optimal level of initial investment. As stated in problem (6) we maximize the indirect utility function of owner 1 (since by assumption $\bar{\theta}^{1} \geq 0.5$ ):

$$
V^{1}(k)=\frac{1}{1-\gamma}\left[\beta \omega+\left(\bar{\theta}^{1}-\theta^{1}(k)\right) p(k)-\bar{\theta}^{1} k\right]^{1-\gamma}+\frac{\delta}{1-\gamma}\left[\theta^{1}(k) A k^{\alpha}\right]^{1-\gamma}
$$

Disregarding the non-negativity constraints, the first-order condition reads

$$
\begin{aligned}
\frac{\partial V^{1}(k)}{\partial k} & =\left[\left(\bar{\theta}^{1}-\theta^{1}(k)\right) \frac{\partial p(k)}{\partial k}-\bar{\theta}^{1}\right]\left[\beta \omega+\left(\bar{\theta}^{1}-\theta^{1}(k)\right) p(k)-\bar{\theta}^{1} k\right]^{-\gamma} \\
& +\delta \alpha\left(\theta^{1}(k)\right)^{1-\gamma} A^{1-\gamma} k^{\alpha(1-\gamma)-1}=0
\end{aligned}
$$

where $\frac{\partial p(k)}{\partial k}$ is given in equation (65). In general, problem (6) has to be solved numerically. Still one can see from the first-order condition that the desired level of investment $k$ of owner 1 depends

\footnotetext{
${ }^{36} \lim _{\gamma \rightarrow 0} \frac{\partial p(k)}{\partial k}=A \alpha \delta k^{\alpha-1}>0$.
} 
on her endowments. A similar condition holds for owner 2, and since endowments may be different both optimality conditions will, in general, not coincide. Our simulations for reasonable values of $\gamma$ confirm the results of Proposition 2.

Proportional Endowments. We consider the case where $\beta=\bar{\theta}^{1}$. In equilibrium, there is no share trade such that $\bar{\theta}^{i}=\theta^{i}, \quad i=1,2$. The indirect utility function for owner 1 becomes

$$
U^{1}(k)=\frac{1}{1-\gamma}[\beta(\omega-k)]^{1-\gamma}+\frac{\delta}{1-\gamma}\left(\beta A k^{\alpha}\right)^{1-\gamma}
$$

with first-order condition

$$
0=(\alpha \delta)^{-\frac{1}{\gamma}} A^{-\frac{1-\gamma}{\gamma}} k^{\frac{1-\alpha(1-\gamma)}{\gamma}}+k-\omega
$$

In this special case, the optimal level of investment $k$ does not depend on the individual variables $\beta$ and $\bar{\theta}^{1}$, so shareholders will be unanimous. The same result would be obtained if a single owner maximizes utility. ${ }^{37}$

Next, we study how the optimal investment implicitly given by (69) changes when agents become more or less willing to substitute consumption across time (smaller or larger value of $\gamma$ ). Let $F$ be the right-hand side of equation (69) and $G=(\alpha \delta)^{-\frac{1}{\gamma}} A^{-\frac{1-\gamma}{\gamma}} k^{\frac{1-\alpha(1-\gamma)}{\gamma}}$, the first term of the right-hand side. Then

$$
\frac{d k}{d \gamma}=-\frac{\partial F / \partial \gamma}{\partial F / \partial k}=-\frac{\partial G / \partial \gamma}{\partial G / \partial k+1}
$$

For the partial derivatives we find the following signs

$$
\begin{aligned}
\frac{\partial G}{\partial k} & =(\alpha \delta)^{-\frac{1}{\gamma}} A^{-\frac{1-\gamma}{\gamma}} \frac{1-\alpha(1-\gamma)}{\gamma} k^{\frac{1-\alpha(1-\gamma)-\gamma}{\gamma}}>0 \\
\frac{\partial G}{\partial \gamma} & =G \frac{\partial(\ln G)}{\partial \gamma}=\frac{G}{\gamma^{2}}[\ln (\alpha \delta A)-(1-\alpha) \ln k] \\
& \lesseqgtr 0 \text { if } k \gtreqless(\alpha \delta A)^{\frac{1}{1-\alpha}}
\end{aligned}
$$

Since $\partial G / \partial k$ is positive, the sign of $d k / d \gamma$ is the opposite of $\partial G / \partial \gamma$, for example for the case $k>(\alpha \delta A)^{\frac{1}{1-\alpha}}$ we have that $k$ is increasing in $\gamma$. If we use (69) again, we can derive the following condition:

$$
(\alpha \delta A)^{\frac{1}{1-\alpha}}\left[1+(\alpha \delta)^{\alpha}\right]-\omega \lesseqgtr 0 \quad \Leftrightarrow \quad k \gtreqless(\alpha \delta A)^{\frac{1}{1-\alpha}} \quad \Leftrightarrow \quad \frac{d k}{d \gamma} \gtreqless 0
$$

An agent with low $\gamma$ would make the investment decision mainly according to the return of the technology. If the technology has relatively low returns (low $A$ ) or the endowment $\omega$ is relatively

\footnotetext{
${ }^{37}$ Note that one could cancel $\beta$ from the indirect utility function above.
} 
large, an owner with low $\gamma$ would invest few amounts, while an owner with higher desire to smooth consumption (high $\gamma$ ) would invest more - investment is increasing in $\gamma$.

Special Case $\gamma=0$. It is instructive to specialize further to the case where $\gamma=0$, i.e. the agents do not care about consumption smoothing at all. The optimal level of investment in this case is $k=(\delta A \alpha)^{\frac{1}{1-\alpha}}$ (while it does not exceed $\omega$ ). Note that this is the same investment rule as under complete markets (appendix B), only with the market discount factor $\frac{1}{1+r}$ replaced by the subjective discount factor $\delta$.

\section{References}

Admati, Anat R., Paul Pfleiderer, and Josef Zechner (1994): Large Shareholder Activism, Risk Sharing, and Financial Market Equilibrium, The Journal of Political Economy, 102(6), 1097-1130.

Aiyagari, S. Rao (1994): Uninsured Idiosyncratic Risk and Aggregate Saving, The Quarterly Journal of Economics, 109(3), 659-684.

Bolton, Patrick, Marco Becht and Ailsa Röell (2003): Corporate Governance and Control, in: Constantinides, G.M, M. Harris, and R. Stulz, eds., Handbook of the Economics of Finance (Ch. 1), NorthHolland.

Carceles-Poveda, Eva and Daniele Coen-Pirani (2005a): Shareholder Unanimity with Incomplete Markets, Working Paper.

Carceles-Poveda, Eva and Daniele Coen-Pirani (2005b): Capital Ownership under Market Incompleteness: Does It Matter? Working Paper.

DeMarzo, Peter (1993): Majority Voting and Corporate Control: The Rule of the Dominant Shareholder, Review of Economic Studies, 60, 713-734.

DeMarzo, Peter and Branko Urošević (2006): Ownership Dynamics and Asset Pricing with a Large Shareholder, The Journal of Political Economy, 114(4), 774-815.

Diamond, Peter A. (1967): The Role of a Stock Market in a General Equilibrium with Technological Uncertainty, The American Economic Review, 57, 759-776.

Drèze, Jaques H. (1974): Investment under Private Ownership: Optimality, Equilibrium, and Stability, in: Jaques H. Drèze, ed., Allocation under Uncertainty Equilibrium and Optimality (Ch.9), New York; reprinted in: Jaques H. Drèze (1987): Essays on Economic Decisions under Uncertainty (Ch.14), Cambridge.

Drèze, Jaques H. (1985): (Uncertainty and) The Firm in General Equilibrium Theory, The Economic Journal, 95 (Supplement: Conference Papers), 1-20.

Drèze, Jaques H. (1987): Decision Criteria for Business Firms, in: Jaques H. Drèze, Essays on Economic Decisions under Uncertainty (Ch.15), Cambridge.

Drèze, Jaques H. (1989): Labour Management, Contracts and Capital Markets, Oxford/New York.

Edelstein, Robert H., Branko Urošević, and Nicholas Wonder (2005): Ownership Dynamics of REITs, Journal of Real Estate Finance and Economics, 30, 447-466.

Ekern, S. and R. Wilson (1974): On the Theory of the Firm in an Economy with Incomplete Markets, The Bell Journal of Economics, 5, 171-180.

Grossman, Sanford J. and Oliver D. Hart (1979): A Theory of Competitive Equilibrium in Stock Market Economies, Econometrica, 47(2), 293-329. 
Grossman, Sanford J. and Joseph E. Stiglitz (1980): Stockholder Unanimity in Making Production and Financial Decisions, The Quarterly Journal of Economics, 94(3), 543-566.

Hubbard, R. Glenn (1998): Capital-Market Imperfections and Investment, Journal of Economic Literature, $36(1), 193-225$.

Kelsey, David and Frank Milne (1996): The Existence of Equilibrium in Incomplete Markets and the Objective Function of the Firm, Journal of Mathematical Economics, 25, 229-245.

Kelsey, David and Frank Milne (2006): Externalities, Monopoly and the Objective Function of the Firm, Economic Theory, 29, 565-589.

La Porta, Rafael, Florencio Lopez-de-Silanes, Andrei Shleifer, and Robert W. Vishny (1998): Law and Finance, The Journal of Political Economy, 106, 1113-1155.

Magill, Michael and Martine Quinzii (1996): Theory of Incomplete Markets. Cambridge, Mass.

Massa, Massimo and Andrei Simonov (2005): Shareholder Homegeneity and Firm Value - The Disciplining Role of Non-Controlling Shareholders, Working Paper.

Mikkelson, Wayne, Megan Partch and Kshitij Shah (1997): Ownership and Operating Performance of Companies that Go Public, Journal of Financial Economics 44(3), 281-307.

Modigliani, Franco and Merton H. Miller (1958): The Cost of Capital, Corporation Finance, and the Theory of Investment, The American Economic Review, 48, 261-297.

Radner, Roy (1974): A Note on Unanimity of Stockholders' Preferences among Alternative Production Plans: A Reformulation of the Ekern-Wilson Model, The Bell Journal of Economics, 5, 181-186.

Shleifer, Andrei and Robert W. Vishny (1997): A Survey of Corporate Governance, The Journal of Finance, $52(2), 737-783$.

Sprenger, Carsten (2002), Ownership and Corporate Governance in Russian Industry: A Survey, EBRD Working Paper No. 70.

Sprenger, Carsten (2005): The Determinants of Ownership after Privatization — the Case of Russia, presented at the Annual Conference of the European Finance Association 2005, available at http://ssrn.com/abstract $=676882$.

St-Pierre, Marc (2005): Technology and Value of a Firm in Incomplete Market Economies with Stock Market, Working Paper.

Urošević, Branko (2002), Moral Hazard and Dynamics of Insider Ownership Stakes, Working Paper No. 787, Department of Economics and Business, Universitat Pompeu Fabra.

Yalcin, Erkan and Thomas Renström (2003): Endogenous Firm Objectives, Journal of Public Economic Theory, 5(1), 67-94. 